\title{
Consumo de alimentos e alguns nutrientes em Manaus, Amazonas. 1973-4 $\left(^{*}\right)$
}

R. Shrimpton ( ${ }^{*}$ )

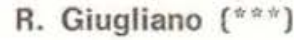

\begin{abstract}
Resumo
Dados de consumo de alimentos e ingestão de nutrientes na Amazônia são escassos. Foram analisados dados já existentes da Primeira Fesquisa sobre Orçamentos Familiares feita entre 1.200 familias de Manaus, em 1973 e 1974, pela CODEAMA. A dieta caracteriza-se pelo baixo consumo de verduras, legumes, frutas e leguminosas secas, além do alto consumo de peixe, pão e farinha de mandioca. Do ponto de vista quantitativo a dieta parece suficiente ao nível familiar, mas em termos qualitati vos é deficiente, com niveis baixos de Vitaminas A e B. Medidas e políticas capazes de melhorar esse quadro em relação aos problemas de Saúde Pública atuais e futuros, são discutidas.
\end{abstract}

\section{INTRODUÇĀo}

Existe uma quantidade considerável de trabalhos sobre consumo quantitativo de alimentos para várias partes do Brasil (Fundação Getúlio Vargas, 1970; ICNND, 1965; Jansen et al., 1977; Fundação IBGE, 1977, a e b), mas só conhecemos um que trate de quantidade de alimentos consumidos no Norte do País (Silva, 1959). Neste levantamento feito pela Comissão Nacional de Alimentação (CNA) foram estudadas 734 famílias oriundas de 15 sedes municipais, situadas entre as melhores do ponto de vista sócio-econômico (Batista, 1976). Os resultados foram apresentados sem análise profunda e mostram um quadro não alarmante de alimentação na Amazônia. Entretanto, são muitas as observações subjetivas sobre a precariedade da situação nutricional e alimentar na Bacia Amazônica (Hanson, 1933; Spix \& Von Martius, 1938; Castro, 1965; Costa, 1948; Wisniewsky \& Lisbonati, 1967; Chaves, 1972; Batista, 1976). Apesar da Bacia Amazônica representar cerca de metade do Território Nacional, com grandes diferenças de uma região para a outra, o estudo da CNA incluiu dados quantita. tivos sobre consumo de alimentos em apenas 3 cidades do interior do Estado do Amazonas, sem analisá-los separadamente dos outros centros urbanos estudados.

O Estado do Amazonas é o maior em área dos estados brasileiros, sendo maior do que a Colômbia, terceiro maior país da América do Sul. A ocupação produtiva dessa imensa área é enfatizada no II Plano Nacional de Desenvolvimento (II PND). Manaus, capital do Estado, após a instalação da Zona Franca em 1967, vem apresentando uma das maiores taxas de crescimento das cidades brasileiras (Fundaçăo IBGE, 1971 a.), recebendo um afluxo constante de famílias provenientes da área rural do Estado. Este êxodo rural é tão grande que, de 1960 a 1975 , a proporção da população rural do Estado diminuiu de $66,9 \%$ para $53,2 \%$ (CODEAMA, 1976 a).

Reconhecendo a falta de dados recentes sobre consumo de alimentos no Norte do Brasil resolvemos analisar os dados da I Pesquisa Orçamentária Familiar (IPOF) realizada pela Comissão de Desenvolvimento do Estado do Amazonas (CODEAMA) em 1.200 familias de Manaus durante o período entre 1973 e 1974. Esse estudo incluiu dados sobre compras de alimentos, que analisamos para verificar principalmente a frequência e quantidade de alimentos consumidos, além da suficiência de alguns nutrientes ao nivel familiar.

\section{METODOLOGIA}

Os dados analisados são os resultados da I Pesquisa Orçamentária Familiar (IPOF), feita pela CODEAMA em colaboração com a Fundação Getúlio Vargas em 1973-1974 (CODEAMA,

\footnotetext{
(*) - Projeto no 2017/17. CNPq-INPA.

(*) - Instituto Nacional de Pesquisas da Amazônia, Manaus

(*) - Instituto Nacional de Pesquisas da Amazônia e Ins tituto de Medicina Tropical. Manaus.
} 
1977b). Essa pesquisa incluiu os alimentos comprados mensalmente por 1.200 famíilas na base de 100 familias por mês, durante doze meses, baseada em métodos conhecidos (REH, 1962).

\section{AMOSTRAGEM}

Baseada na lista da Companhia de Eletricidade de Manaus (CEM) foram selecionadas 6.000 residências e feita uma pesquisa cadastral que mostrava que $19,8 \%$ da população do cadastro tinha renda familiar até 2,2 salários mínimos, $40,6 \%$ entre 2,2 e 5,2 salários e $39,6 \%$ acima de 5,2 salários mínimos. As famílias selecionadas para o IPOF pela CODEAMA, como amostra representativa da cidade, foram sorteadas usando a lista dos clientes da CEM e estratificada por renda de mesma maneira que na pesquisa cadastral. Nós escolhemos estes três grupos de renda para analisar os aspectos de consumo de alimentos, tendo em vista que é reconhecido que famílias com renda de 2 salários mínimos ou menos, são as mais prováveis de terem deficiências alimentares.

\section{CONSUMO DE ALIMENTOS E NUTRIENTES}

As freqüências dos alimentos citados como comprados foram analisadas, por classes de renda, para ver se haveria algum efeito sobre o comportamento das freqüências. O consumo per capita por dia de cada alimento foi calculado, baseado na quantidade total comprada no mês, menos $10 \%$ para perdas eventuais, dividida pelo número total de pessoas na amostra e pelos 30 dias do mês (Anexo 1).

Dos alimentos que eram consumidos em quantidades de uma grama per capita por dia ou mais, foram calculadas as quantidades consumidas de proteina, gordura, carbohidrato, energia, retinol, riboflavina, tiamina, niacina, ácido ascórbico, cálcio e ferro, baseados em tabelas de composição de alimentos já existentes (Watt \& Merril, 1963; Leung \& Flores, 1961) (Anexo II) .

O consumo recomendado de cada nutriente foi calculado, baseado na estrutura populacional, por classe de renda, usando as recomendações da OMS (WHO, 1961; WHO, 1965; WHO, 1970; WHO, 1973). (Veja Anexo III).

\section{ASPECTOS ANTROPOMÉTRICOS}

Considerando a incerteza associada aos métodos para avaliar suficiência de energia, decidimos analisar os dados antropométricos coletados na amostra do IPOF. Na população acima de dezoito anos, foi calculado o índice de massa corporal (peso dividido pela altura ao quadrado) (Wormsley \& Durnin, 1977) e dos maiores de 22 anos foi calculada a freqüência de peso acima de $120 \%$ do ideal para altura (Jelliffe, 1966) .

\section{Resultados E DISCUSSÃo}

\section{REPRESENTABILIDADE DA AMOSTRAGEM}

A lista dos clientes da CEM tinha 14.608 registros em março de 1973 (CODEAMA, 1976b). Admitindo uma média de 5,57 pessoas por família, encontrada pela CODEAMA, temos um total de 260.732 pessoas que representariam $77,1 \%$ da população de Manaus estimada. na época, pela própria CODEAMA (CODEAMA, 1976 a). Admitindo que, pelo menos, 22,9\% da população da cidade não tinha eletricidade e que provavelmente caberiam melhor dentro do grupo de renda de 0-2,2 salários mínimos foi possível estimar a distribuiçăo real de renda da cidade na época. Assim temos 38\% com $0-2,2$ salários mínimos, $31,1 \%$ com $2,2-5,2$ salários e $30,5 \%$ com 5,2 salários mínimos ou mais (Tabela 1).

$\mathrm{Na}$ amostragem do IPOF, a distribuição da população por renda dentro das 1.200 famílias foi de $3,9 \%$ no grupo de baixa renda, $43,2 \%$ no grupo de média e $52,8 \%$ no grupo de alta renda. Rieconhecendo que a desnutrição é sempre um fator associado à pobreza, o grupo de baixa renda que é o grupo de maior interesse em termos nutricionais e representa a maioria da população, infelizmente, está menos representado ne amostra do IPOF.

O problema de conseguir uma amostragem representativa para fins nutricionais é sempre difícil. O IPOF usou a lista da CEM. O IBGE, para fazer o ENDEF, usou a lista eleitoral. Uma cidade como Manaus, em fase de rápido crescimento e recebendo grande afluxo de pessoas da área rural, que se instalam em "fa- 
TABELA 1 - Distribuição de renda na amostra ge ral do IPOF e na população de Manaus. 1973-1974.

\begin{tabular}{|c|c|c|c|c|}
\hline $\begin{array}{c}\text { Grupo } \\
\text { de } \\
\text { renda }\end{array}$ & $\begin{array}{l}\text { Salários } \\
\text { mínimos }\end{array}$ & $\begin{array}{c}\% \text { da } \\
\text { popula- } \\
\text { ção * }\end{array}$ & $\begin{array}{l}\text { \% da po- } \\
\text { pulação } \\
\text { em cada } \\
\text { grupo de } \\
\text { renda" }\end{array}$ & $\begin{array}{c}\% \text { da } \\
\text { amostra } \\
\text { do IPOF } \\
\text { em cada } \\
\text { grupo de } \\
\text { renda }\end{array}$ \\
\hline Baixa & $0-2,2$ & 38,14 & 38,1 & 3,9 \\
\hline Média & $\begin{array}{l}2,2-3,5 \\
3,5-\quad 5,2\end{array}$ & $\begin{array}{l}16,24 \\
15,09\end{array}$ & 31,3 & 43,2 \\
\hline $\begin{array}{c}\text { Alta } \\
\text {. }\end{array}$ & $\begin{array}{r}5,2-8,0 \\
8,0-12,0 \\
12,0-18,0 \\
18,0-25,0 \\
25,0-35,0 \\
35,0-50,0 \\
50,0-75,0 \\
75,0-100,0 \\
100,0-\text { mais }\end{array}$ & $\begin{array}{r}11,76 \\
7,68 \\
5,28 \\
3,01 \\
1,61 \\
0,79 \\
0,27 \\
0,13 \\
0,02\end{array}$ & 30,6 & 52,8 \\
\hline
\end{tabular}

(*) Estimativa dos Autores (vide texto).

velas" na periferia da cidade, sem infraestrutura e cadastramento e constantemente migrando, dificulta bastante a escolha de uma amostragem representativa. Essa população representa uma razoável proporção da população geral, vivendo em condições paupérrimas e portanto com maior probabilidade de ter problemas nutricionais, porém, difícil de ser alcançada e enquadrada num inquérito. Assim a amostra de baixa renda do IPOF não é representativa da população de baixa renda de Manaus.

FREQÜÊNCIA DE CITAÇÃO DE ALIMENTOS E EFEITO DA RE:DI

A análise da freqüência de citações de alimentos comprados por mês pela amostra geral demonstra que o sal é o alimento mais freqüentemente comprado $(98,4 \%)$, logo seguido pelo pão $(97,7 \%)$, café em pó $(96,7 \%)$ e cebola $(95,9 \%)$. (Tabela 2$)$.

$\mathrm{O}$ efeito da renda sobre as freqüências de consumo de alimentos do IPOF em Manaus, encontra-se na Tabela 2. O grupo de cereais e derivados sofre pouca influência da renda en- quanto o de raízes e tubérculos mostra que a batata inglesa é mais freqüentemente comprada à medida que aumenta a renda. A farinha seca é mais freqüentemente comprada que a farinha d'água em todas as classes de renda e isto é surpreendente porque num estudo de escolares pobres em Manaus constatamos o oposto (Giugliano et al., 1978a). A compra da farinha d'água do arini, considerada a melhor e mais cara, é feita mais pelos grupos de maior rencla.

A freqüência do consumo de açúcar refinado aumenta com a renda, ao passo que o açúcar grosso, diminui. A goiabada é o doce mais comumente comprado e a freqüência aumenta com a renda. Com relação aos refrigerantes, o consumo de guaraná local ainda permanece o mais freqüente em todas as ciasses de renda. A freqüência de compra de cebola, alho e cheiro-verde como condimento sofre influência da renda, mas ainda é bem difundida. O tomate parece ser menos freqüentemente comprado, com aumento da renda. Verduras folhosas como couve e alface são mais ireqüentemente compradas pelas classes de alta renda.

Das frutas, a banana e limão são as maic freqüentemente compradas e sofrem pouca influência da renda. A frequeência de compra de outras frutas como laranja, mamão, abacaxi é baixa no grupo de menor renda sendo maior nos grupos restantes.

O efeito da renda sobre a freqüência de compra de peixe inclui o declínio do jaraqui com o aumento da renda e a presença do tucunaré, principalmente no grupo de alta renda. O tambaqui era o peixe mais freqüentemente comprado em Manaus, na época do inquérito. A freqüência de consumo de carne bovina (alcatra) aumentou consideravelmente do grupo de baixa e média renda para o de alta renda. A freqüência de consumo de todo o grupo de lacticínios aumenta com a renda, exceto o de leite fresco pasteurizado que tinha baixa freqüência de consumo em todas as classes.

Um estudo pouco conhecido realizado em 1.024 famílias de Manaus em 1943-1944 (Costa \& Silva, 1949), reportou a freqüência do consumo de diferentes alimentos. Uma comparação exata destes dados com os do IPOF não 
TABELA 2 - Efeito da renda sobre a freqüência percentual de consums ds alguns alimentos em Manaus *

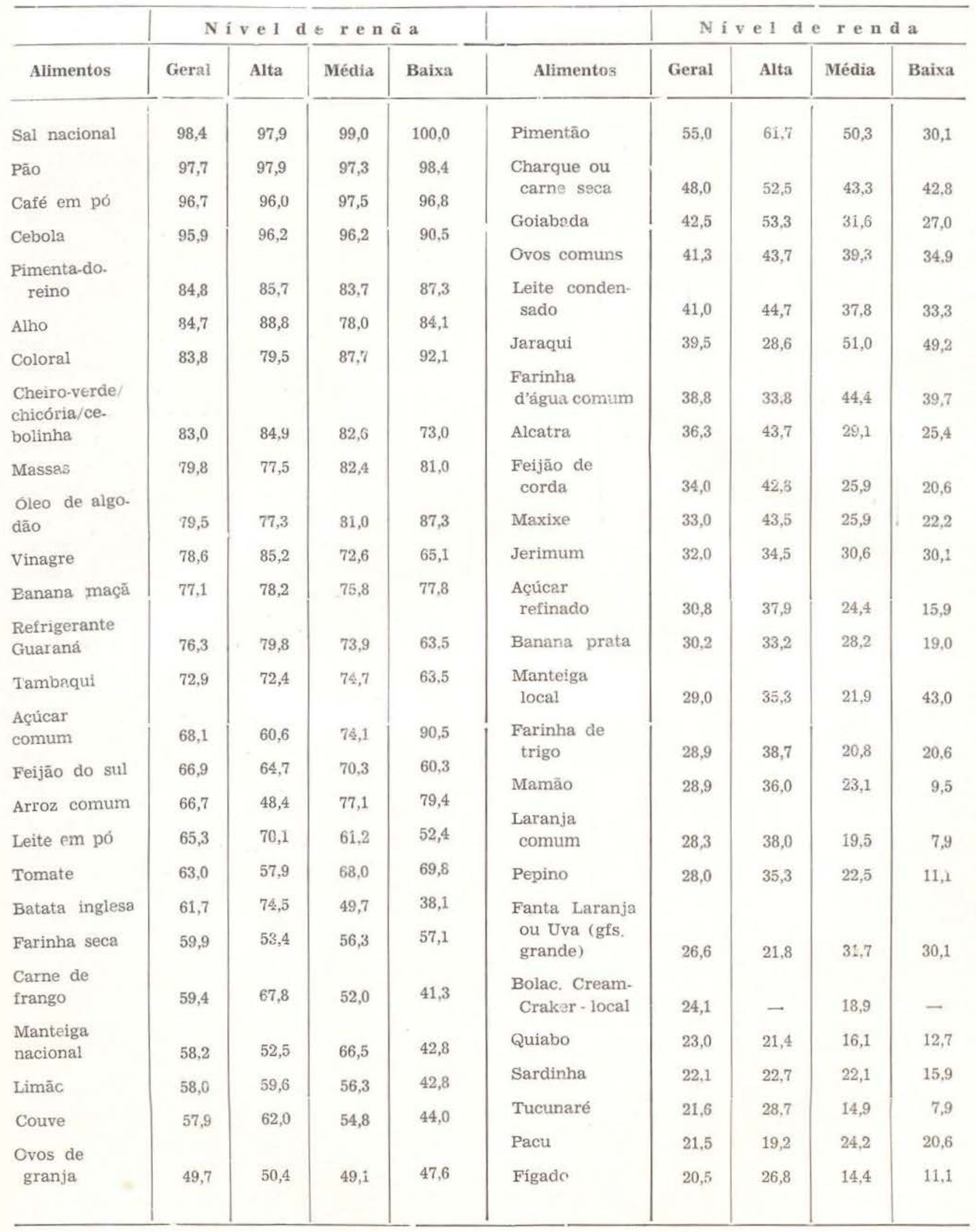

(*) IPOF. 
foi possivel devido aos grupos de alimentos serem diferentes e da não referência se a freqüência do consumo era diária, semanal ou mensal. Admitindo estas diferenças, parece que os alimentos mais freqüentemente consumidos em Manaus, há trinta anos atrás eram. arroz, carne de porco, charque, vísceras e fe:jão e os de menor freqüência queijo, ovos, vegetais folhosos e frutas. O consumo de farinha seca e d'água não era diferenciado no inquérito referido, e o consumo de cheiro-verde não foi constatado. Tomates eram consumidos mais freqüentemente que hoje em dia (Tabela 3) .

TABELA 3 - Composição percentual da freqüência de consumo de alguns alimentos em Manaus em 1943-14, em 1973-74, e em Codajás, 1958.

\begin{tabular}{|c|c|c|c|}
\hline & $\begin{array}{l}\text { Con̉ajás } \\
1958\left({ }^{*}\right)\end{array}$ & $\begin{array}{c}\text { Manaus } \\
1943-4 \\
\left({ }^{\circ * 1}\right)\end{array}$ & $\begin{array}{c}\text { Manaus } \\
1973-4 \\
(\text { (해웅 }\end{array}$ \\
\hline Pão & 76,0 & 96,8 & 97,7 \\
\hline Farinha de mandioca & 98,0 & 97,8 & 98,7 \\
\hline Farinha de milho & 0,6 & 34,6 & 0,0 \\
\hline Outras farinhas & - & 46,2 & 30,0 \\
\hline Macarrão & 10,0 & 31,1 & 79,9 \\
\hline Arroz & 53,0 & 98,3 & 67,7 \\
\hline Carne de boi & 1,8 & 53,0 & $36,3^{* \cdots}$ \\
\hline Carne de porco & 0,6 & 30,1 & 0.0 \\
\hline Outras carnes & 1,5 & 5,1 & 0,0 \\
\hline Charque & $\rightarrow$ & 87,9 & 48,0 \\
\hline Peixe fresco & 75,0 & 96,9 & 100,0 \\
\hline Mariscos & - & 2,4 & 0,0 \\
\hline Galinhas & 1.8 & 51,8 & 59,5 \\
\hline Outras aves & - & $e, 1$ & 0,0 \\
\hline Vísceras & $\rightarrow$ & 40,3 & 20,5 \\
\hline Gorduras & 68,0 & 98,8 & 86,7 \\
\hline Leite em pó & 51,0 & 66,3 & 65,3 \\
\hline Queijo & 1,0 & 2,9 & 9,7 \\
\hline Manteiga & 26,0 & 66,8 & 88.7 \\
\hline Ovos & 34,0 & 52,9 & 91.8 \\
\hline Feijōes & - & 95,3 & 66,9 \\
\hline Vegetais folhosos & 6,6 & 30,0 & 58,0 \\
\hline Tubérculos = raízes & 10,0 & 56,7 & 61,7 \\
\hline $\begin{array}{l}\text { Outras verduras - } \\
\text { legumes }\end{array}$ & 1,8 & 47,4 & 98.0 \\
\hline Tomate & 1,2 & 75,3 & 63,0 \\
\hline Laranja & 41,0 & 4,6 & 28,3 \\
\hline Banana & 84,0 & 87,9 & 77,1 \\
\hline Pupunha & 0,6 & - & - \\
\hline Outras frutas & 12,6 & 20,1 & - \\
\hline
\end{tabular}

\footnotetext{
NOTAS

(*) Liro, 1960

$(\because *)$ ) Costa \& Silva, 1946

$(* *)$ IPOF.

(**) Somente alcatra.
}

Comparações perfeitas com os dados de Lira (1960) em Codajás(") em 1958 não são viáveis pois mais uma vez não está bem claro se a freqüência dos alimentos citados como comprados era mensal, semanal ou diário, além do fato de que muitos alimentos estão agrupados de maneira diferente. Comparaçöes gerais, no entanto, são possiveis e as diferenças mais notáveis são na freqüência de consumo de tomate, que em Codajás foi de $1,2 \%$ e em Manaus de $63 \%$; couve com 1,0\% em Codajás e $59 \%$ em Manaus; pão com $76 \%$ em Codajás e $97,7 \%$ em Manaus. A freqüência de consumo de arroz era semelhante, ao passo que o macarrão aumenta de $10 \%$ em Codajás para $80 \%$ em Manaus.

A freqüência de consumo de banana não é muito diferente, mas a laranja era consumida em dobro em Codajás e o açaí que era $25 \%$ em Codajás passa a ser insignificante em Manaus. A freqüência do consumo de mamão foi de $0.6 \%$ em Codajás e $29 \%$ em Manaus.

A freqüência de consumo de peixe fresco continua sendo onipresente em ambas as dietas. A carne era pouco freqüente em Codajás, atingindo somente $1,8 \%$, enquanto que em Manaus, considerando-se somente a freqüência de alcatra, ela atinge $36,6 \%$. O consumo de galinha também mudou de 1,8\% em Codajás para $59 \%$ em Manaus. Leite em pó atingia $51,0 \%$ em Codajás, mas distribuído de graça pela FISI, enquanto que em Manaus é de $65 \%$, mas é comprado. A ausência de cebola, cheiro-verde e limão no trabalho de Lira é surpreendente, enquanto que a ausência de feijão está de acordo com recente inquérito que realizamos em populações ribeirinhas do rio Solimões.

\section{CONSUMO DE ALIMENTOS}

O consumo por grupo de alimentos e por renda é apresentado na Tabela 4 . O consumo dos grupos de baixa e média renda na amostra estudada não é muito diferente, mas muda bastante no grupo de alta renda na população geral de Manaus. Estimamos que os grupos de baixa e média renda representam cerca de $70 \%$ da população, enquanto na amostra do IPOF representa somente $47 \%$ (Tabela 1). Isto é refletido no consumo do grupo geral da amostra 
que sofre muito mais a influência do grupo de alta renda do que dos grupos de baixa e média rendas que predominam na população de Manaus.

Considerando-se a semelhança do consumo dos grupos de média e baixa renda e a restrita participação porcentual deste último grupo na amostragem escolhicia, tivemos que usar os valores de faixá de média renda como representativa do consumo global da cidade, e não o consumo da amostra geral do IPOF.

$O$ inquérito nutricional do CNA na Bacia Amazônica (Silva, 1959) usou 3 cidades do interior do Amazonas: Benjamim Constant, Maués e Tefé, nas quais foram estudadas 73 famílias, totalizando 588 pessoas. Analisando os dados sobre o consumo em cada cidade é possivel chegar às médias de consumo diário per capita e que estão na Tabela 5. Comparando tais dados com o da classe de média renda do IPOF, observamos diferenças interessantes. Em Manaus, o pobre dos dias de hoje parece consumir menor quantidade de farinha de mandioca, ao passo que consome mais pão. Nota- se que a farinha na dieta encontrada pelo CNA foi, predominantemente, farinha d'água, enquanto encontramos a farinha seca como a mais consumida no IPOF.

$O$ consumo de frutas em geral foi o dobro no inquérito do CNA comparado com a amostra de média renda em Manaus. As frutas consumidas nas cidades do interior do Estado foram diferentes de Manaus onde o consumo principal foi de limão, mamão, maracujá, abacaxi e abacate, enquanto no interior predominava taperebá, beribá, laranja e goiaba .

Nas cidades do interior a carne bovina era muito menos consumida do que em Manaus hoje em dia. O consumo de legumes em Manaus e no inetrior, foi praticamente o mesmo, mas os tipos de legumes foram bem diferentes. No interior foi observado principalmente o consumo de abóbora (jerimum), enquanto não apareceram couve, alface, feijão-de-corda, tomate e cheiro-verde, os quais foram os mais comuns em Manaus, O cheiro-verde é tāo comum nas dietas da classe pobre de Manaus que nos deixa a pensar como não foi citado nas dietas do CNA.

TABELA 4 - Consumo por grupo de alimcntos em gramas per capita/dia e classe de renda $\mathrm{cm} 1260$ famílias de Manaus - 1973.74\%

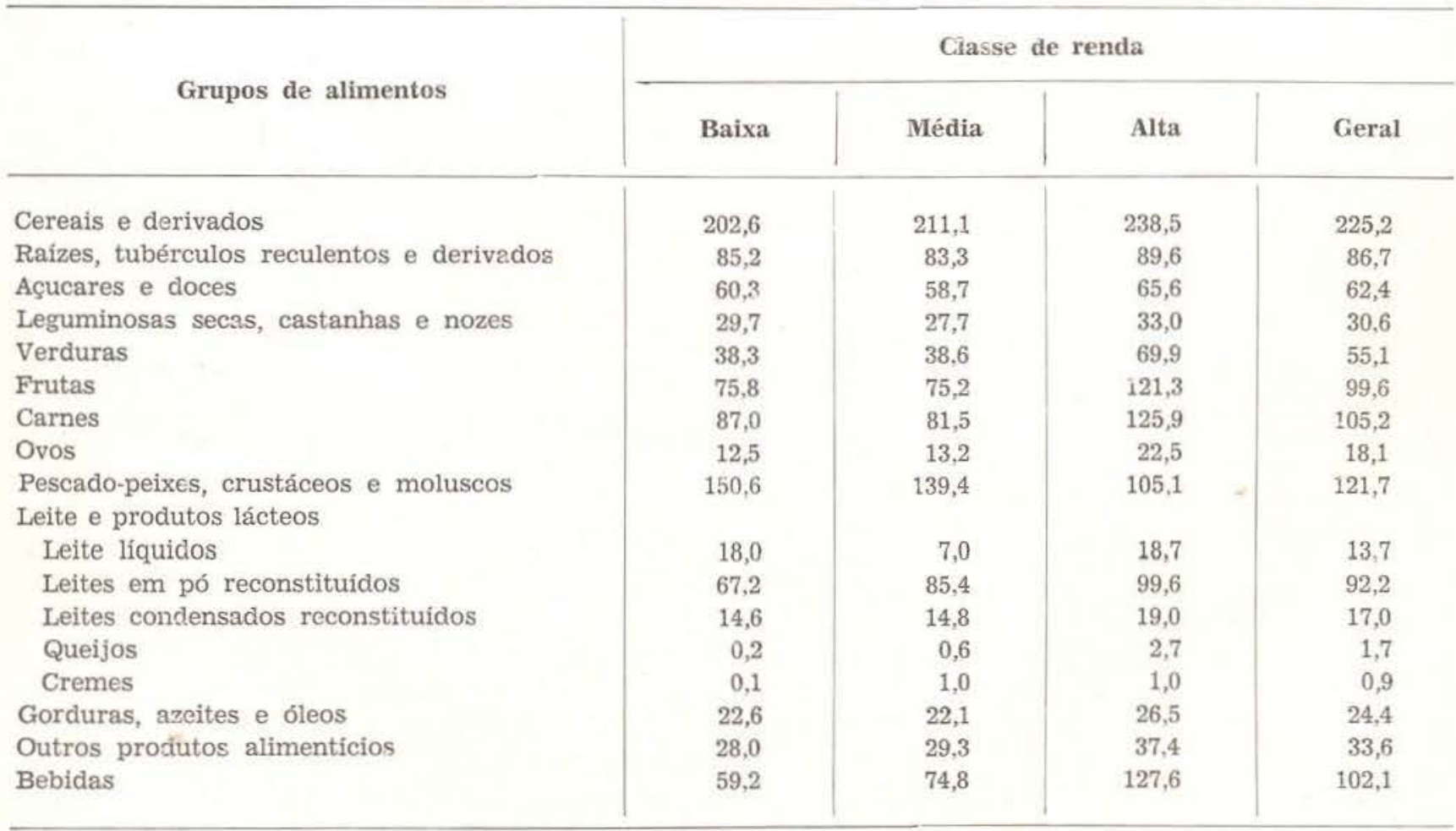

(•) IPOF - 
TABELA 5 - Consumo de alimentos em gramas per capita por dia em 3 cidades do Amazonas 1953-54 (Silva, 1959), comparado com a classe de média renda em Manaus 1973-1974 (IPOF)

\begin{tabular}{|c|c|c|}
\hline & $\begin{array}{c}1953-1954 \\
\text { Manaus }\end{array}$ & $\begin{array}{c}1973-1974 \\
\text { Interior }\end{array}$ \\
\hline Pão & 78,2 & 113,8 \\
\hline Arroz & 47,2 & 73,8 \\
\hline Maizena & 1,3 & 1,5 \\
\hline Macarrão & 9,9 & 12,2 \\
\hline Farinha d'água & 122,5 & 34,9 \\
\hline Farinha seca & 19,8 & 34,9 \\
\hline Carne de boi verde & 14,1 & 60,8 \\
\hline Porco & 4,8 & 0,0 \\
\hline Conserva & 1,9 & 0,5 \\
\hline Charque & 1,8 & 2,6 \\
\hline Peixe fresco & 56,3 & 122,9 \\
\hline Pirarucu seco & 16,2 & 1,6 \\
\hline Galinha & 7,1 & 14,2 \\
\hline Leite fresco & 34,8 & 0,9 \\
\hline Leite em pó & 1,7 & 74,0 \\
\hline Leite condensado & 6,3 & 14,9 \\
\hline Manteiga & 1,9 & 6,8 \\
\hline Ovos & 11,1 & 13,3 \\
\hline Beribá & 5,3 & 0,0 \\
\hline Banana & 87,1 & 52,4 \\
\hline Goiaba & 7,5 & 0,0 \\
\hline Laranja & 8,6 & 3,7 \\
\hline Taperebá & 11,8 & 0,0 \\
\hline Couve & 1,7 & 2,3 \\
\hline Maxixe & 3,7 & 1,5 \\
\hline Abobora & 16,2 & 3,5 \\
\hline Batata inglesa & 1,9 & 6,8 \\
\hline Batata doce & 2,1 & 5,4 \\
\hline Cará & 1,6 & 0,9 \\
\hline Macaxeira & 30,5 & 0,4 \\
\hline Feijão & 27,7 & 27,8 \\
\hline Banha & 4,8 & 0,0 \\
\hline Açúcar & 48,5 & 56,6 \\
\hline Café & 9,1 & 11,5 \\
\hline Cerveja & 1,0 & 2,4 \\
\hline Cebola & 2,2 & 7,8 \\
\hline Goiabada & 1,9 & 2,1 \\
\hline Sal & 10,0 & 9,0 \\
\hline Vinagre & 2,3 & 2,7 \\
\hline
\end{tabular}

O consumo de batata doce, batata inglesa e cará são mais altos em Manaus, ao passo que mandioca (macaxeira) tinha um alto consumo no interior. Feijão preto do sul é o mais consumido no interior e em Manaus. O consumo de feijão local (feijão-da-praia), é muito baixo embora sendo mais barato do que o feijão importado do sul.
Os resultados preliminares do recente inquérito Nacional de Despesas Familiares (Fundação IBGE, 1977 a e b) feito em 1975-76, permite a comparação dos dados de Manaus com o restante do país. Na tabela 6 estes resultados são comparados. O consumo do grupo de média renda de Manaus, quando comparado com os resultados preliminares do ENDEF, em Belo Horizonte, Recife, Fortaleza e São Paulo mostra que o mais baixo consumo de leguminosas está em Manaus. Isto se deve ao hábito de consumir feijão ser bem menos difundido no Norte do que no resto do país. Temos constatado na área rural do Amazonas que o consumo de feijão é raridade para o caboclo. O consumo de verduras é um terço do de São Paulo, e o de frutas é o mais baixo das cinco cidades. O consumo de carne é razoável especialmente considerando o consumo de peixe, que é marcante. O consumo de peixe em Manaus, é sete vezes maior do que em Fortaleza.

Em comparação com os países desenvolvidos (tabela 7), a diferença marcante na dieta manauara está no consumo de verduras, raizes e leguminosas secas correspondendo à metade do consumo dos países desenvolvidos. O consumo de frutas, carne e ovos também é menor, sendo que o de peixe é sete vezes maior que nos países considerados. O governo inglês tem recomendado a diminuição do consumo de carne e ovos em favor de peixe (Department of Health and Social Security, 1974) como uma das medidas para evitar doenças degenerativas e assim podemos considerar este alto consumo de peixe em Manaus como satisfatório. O consumo de leite e derivados é baixo em Manaus, mas o leite de vaca não era alimento de grance consumo na maioria das sociedades e civilizações antes do início do século e do advento da tecnologia de secagem, enlatamento e refrigeração (Simoons, 1978; Jelliffe, 1968). Realmente os conceitos sobre a necessidade do leite na dieta tem mais bases emocionais do que científicas e devem-se principalmente aos esforços das indústrias de laticínios em promover o consumo dos seus produtos (Berg, 1973: Muller, 1974). Sem dúvida o leite é um bom alimento mas não é essencial nem insubstituível na dieta depois do segundo ano de vida. Em algumas pessoas até não é tolerável em grande quantidade (Garzia \& Scrimshaw, 1976; Rosenweig, 1973) . 
TABELA 6 - Consumo de grupos de alimentos, em gramas per capita por dia em Manaus(*) em comparação com algumas outras cidades do Brasil $(* *)$

\begin{tabular}{|c|c|c|c|c|c|}
\hline Grupos de alimentos & São Paulo & $\begin{array}{c}\text { Belo } \\
\text { Horizonte }\end{array}$ & Recife & Fortaleza & $\begin{array}{l}\text { M a n a u s } \\
\text { Média - renda }\end{array}$ \\
\hline Cereais e derivados & 233 & 233 & 213 & 165 & 211,1 \\
\hline Tubérculos e raízes & 56 & 56 & 113 & 68 & 83,3 \\
\hline Açúcares e derivados & 69 & 93 & 76 & 58 & 58,7 \\
\hline Leguminosas e oleaginosas & 54 & 46 & 58 & 74 & 29,7 \\
\hline Legumes (folhas-verduras) & 117 & 95 & 69 & 32 & 38,8 \\
\hline Frutas & 140 & 93 & 115 & 95 & 75,2 \\
\hline Carnes & 104 & 83 & 84 & 68 & 81,5 \\
\hline Pescados & 5 & 7 & 14 & 22 & 139,4 \\
\hline Ovos, leites, queijos & 169 & 165 & 27,7 & 97 & 121,0 \\
\hline Bebidas & 58 & 59 & 15,8 & 28 & 74,8 \\
\hline óleos e gorduras & 40 & 35 & 5,8 & 14 & 22,6 \\
\hline
\end{tabular}

$(*)$ IPOF -

(*) ENDEF - (Fundação IBGE, 1977 a e b).

\section{CONSUMO DE NUTRIENTES}

O consumo per capita por dia dos nutrientes estăo na Tabela 8 e as recomendações per capita por dia para os mesmos estão na Tabela 9. A suficiência destes nutrientes per capita por dia em Manaus é mostrada na Tabela 10 , em comparação com outras 4 capitais estaduais no Brasil, incluidas no I ENDEF (Fundação IBGE, 1977 a e b).

\section{Energia e Proteína}

A preocupação mundial com proteínas na década passada não era realista (Wateriow \& Payne, 1975; McLaren, 1975) e já está bem claro que em outras partes do mundo (Sukatme, 1977; Waterlow \& Rutishauser, 1976) e no Brasil (Shrimpton, 1976; Salomon \& Doréa, 1977) a deficiência de proteína raramente existe sem deficiência de energia concomitante.

$\mathrm{Na}$ maioria das dietas habituais no mundo a quantidade e a concentração das proteínas consumidas, são suficientes para atender às demandas do organismo quando o consumo energético é adequado. O que falta geralmente é energia por um consumo insuficiente na dieta habitual. As estimativas dos requerimentos proteicos são válidas somente quando as necessidades energéticas estão satisfeitas. Se o consumo de energia não é suficiente, as proteínas não são utilizadas eficientemente, sendo então usadas para fornecer energia, conduzindo a um balanço nitrogenado negativo. É irracional aumentar o consumo proteíco para corrigir perdas de proteínas pelo corpo sendo mais lógico e barato corrigir o deficit energético (Crim \& Munro 1977).

As causas do baixo consumo de alimentos da dieta habitual são várias e incluem a produção insuficiente seja por causa de má coIheita por solos pobres, seca etc, ou a incapacidade de comprar por falta de recursos. Além dos problemas de fornecimento existe a incapacidacie de ingerir alimentos suficientes o que inclui problemas relacionados a densidade proteíca e/ou energética. O volume grande de alimentos contendo muita água e fibras mas poucos nutrientes "enche a barriga", sem satisfazer as necessidades nutricionais, especialmente nas crianças depois do ćesmame com a mudança para dieta adulta. A freqüência de refeições do adulto, ou seja, 3 a 4 vezes ao dia com una densidacie energética própria exigiria que a criança, por exemplo, comesse talvez seis vezes ao dia, para satisfazer suas próprias necessidades. Como sabemos, a crianca por catsa das demandas do crescimento, tem necessiciades energéticas e portéicas maicres por q̧uilo de peso do que adulto. Outra causa da reduzida ingestão de alimentos é a 
TABELA 7 - Comparação do consumo de alimentos em gramas per capita por dia em alguns países desenvolvidos( $\left(^{*}\right)$ com Manaus("*)

\begin{tabular}{|c|c|c|c|c|}
\hline \multirow{3}{*}{$\begin{array}{l}\text { Grupos de } \\
\text { alimentos }\end{array}$} & \multicolumn{4}{|c|}{ Localidade e época } \\
\hline & G.B. & MCE & EUA & Manaus \\
\hline & 1965 & $1963-65$ & 1955 & 1973-74 \\
\hline $\begin{array}{l}\text { Cereais e } \\
\text { derivados }\end{array}$ & 246 & 346 & 207 & $211-1$ \\
\hline $\begin{array}{r}\text { Açúcares e } \\
\text { derivados }\end{array}$ & 77 & 57 & 69 & 58.7 \\
\hline $\begin{array}{l}\text { Leguminosas } \\
\text { secas, raízes, } \\
\text { tubérculos e } \\
\text { verduras }\end{array}$ & 320 & 376 & 305 & 149.6 \\
\hline Frutas & 108 & 114 & 184 & 75.2 \\
\hline Carnes & 137 & 118 & 206 & 81.5 \\
\hline Ovos & 34 & 21 & 47 & 13.2 \\
\hline $\begin{array}{l}\text { Pescado (pei- } \\
\text { xes, molus- } \\
\text { cos e crus- } \\
\text { táceos) }\end{array}$ & 21 & 22 & 22 & 139.4 \\
\hline Leite & 382 & 287 & 508 & 107.2 \\
\hline $\begin{array}{l}\text { Gorduras, } \\
\text { azeites e } \\
\text { óleos }\end{array}$ & 44 & 63 & 49 & 22.1 \\
\hline
\end{tabular}

$(* *)-$ IPOF

(*) - Snyder et al. 1975.

$\mathrm{GB}=$ Grô-Bretanha.

MCE = Mercodo Comum Europeu

EUA $=$ Estados Unidos.

Manaus $=I P O F$, média renda. anorexia comumente associada aos processos infecciosos. Qualquer infecção, além de produzir balanço negativo de nitrogênio se associa com uma redução do apetite e consumo de alimentos. Dos processos infecciosos, a diarréia, o sarampo e a malária, já foram implicados como os que mais atrapalham a ingestão de alimentos e o crescimento em outras partes do mundo (Mata et al., 1977; Whitehead et al., 1976).

Os alimentos fornecedores de $90 \%$ da energia e proteína nas dietas das famílias de média renda em Manaus estão discriminados na Tabela 11. Destaca-se o pão, que fornece mais energia do que qualquer outro alimento $\mathrm{e}$ é a terceira maior fonte de proteína. O peixe fornece um terço da proteína total seguido pela carne que colabora somente com metade da quantidade fornecida pelo peixe. A crescente importância do pão merece destaque, pois as importações de trigo pelo Estado quintuplicaram na última década. O hábito de comer pão, tem aumentado na Amazônia incentivado pelos subsídios governamentais que fazem com que o pão tenha o mesmo preço por quilo de peso do que a farinha de mandioca. O trigo é importado pelo Estado e sempre o será e, neste sentido, é difícil entender sua promoção. O arroz seria uma melhor escolha. O pão vem substituindo a farinha na dieta urbana o que não achamos desejável pois a farinha amarela, preferida na Amazônia é possivelmente uma fonte importante de vitamina A (Maravalhas, 1964). O pão tem um conteúdo maior de proteína mas a dieta local é deficiente em vitamina $A$ e não em proteína. A

TABELA 8 - Consumo de nutrientes por classe de renda per capita/dis em 1.200 famílias de Iianaus -1973 a 1974

\begin{tabular}{|c|c|c|c|c|c|c|c|c|c|c|}
\hline $\begin{array}{c}\text { Classe } \\
\text { de } \\
\text { renda }\end{array}$ & & $\begin{array}{c}\text { Energia } \\
\text { CAL }\end{array}$ & $\begin{array}{c}\text { Proteína } \\
\text { GR }\end{array}$ & $\begin{array}{c}\text { Cálcio } \\
\text { MG }\end{array}$ & $\begin{array}{c}\text { Ferro } \\
\text { MG }\end{array}$ & $\begin{array}{c}\text { Vitamina } \\
\text { MCG }\end{array}$ & $\begin{array}{c}\text { Tiamina } \\
\text { MG }\end{array}$ & $\begin{array}{c}\text { Riboflavina } \\
\text { MG }\end{array}$ & $\begin{array}{c}\text { Niacina } \\
\text { MG }\end{array}$ & $\underset{\text { MG }}{\text { Vitamina }}$ \\
\hline \multirow{4}{*}{$\begin{array}{l}\text { Baixa } \\
\text { Média } \\
\text { Alta } \\
\text { Geral }\end{array}$} & \multirow{4}{*}{$=$} & 2086 & $94 . ' t$ & 478 & 16.6 & 332 & 0.71 & 0.92 & 23.1 & 38 \\
\hline & & 2100 & 834 & 506 & 16.3 & 448 & 0.69 & 0.93 & 31.1 & 42 \\
\hline & & 2440 & 93.5 & 623 & 19.2 & 814 & 0.78 & 1.15 & 23.0 & 69 \\
\hline & & 2279 & 88.8 & 567 & 17.9 & 636 & 0.75 & 1.05 & 23.1 & 56 \\
\hline
\end{tabular}

FONTE : IPOF. 
TABELA 9 - Consumo recomendado de nutrientes por classe de renda per capita/dia $\mathrm{cm} 1209$ familias de Manaus - 1973 = 1974

\begin{tabular}{l|ccccccccc}
\hline $\begin{array}{c}\text { Classe } \\
\text { de } \\
\text { renda }\end{array}$ & $\begin{array}{c}\text { Energia } \\
\text { CAL }\end{array}$ & $\begin{array}{c}\text { Proteuna } \\
\text { GR }\end{array}$ & $\begin{array}{c}\text { Cálcio } \\
\text { MG }\end{array}$ & $\begin{array}{c}\text { Ferro } \\
\text { MG }\end{array}$ & $\begin{array}{c}\text { Vitamina A } \\
\text { MCG }\end{array}$ & $\begin{array}{c}\text { Tiamina } \\
\text { MG }\end{array}$ & $\begin{array}{c}\text { Riboflavina } \\
\text { MiG }\end{array}$ & $\begin{array}{c}\text { Niacina Vitamina C } \\
\text { MG } \\
\text { MG }\end{array}$ \\
\hline Baixa & 2241 & 41.6 & 553 & 10.4 & 637 & 0.9 & 1.2 & 14.6 & 27 \\
Média & 2279 & 41.6 & 553 & 10.4 & 632 & 0.9 & 1.2 & 14.9 & 27 \\
Alta & 2312 & 42.2 & 551 & 10.8 & 642 & 0.9 & 1.2 & 15.2 & 27 \\
Geral & 2295 & 419 & 552 & -10.6 & 637 & 0.9 & 1.2 & 15.0 & 27 \\
\hline
\end{tabular}

TABELA 10 - Suficiência percentual per capita por dia de nutrientes. Comparação de Manaus( $\left(^{*}\right)$ com algumas outras capitais de Estado do Brasil( ${ }^{\circ}$ )

\begin{tabular}{|c|c|c|c|c|c|c|}
\hline Nutrientes & Cidade & São Paulo & $\begin{array}{c}\text { Belo } \\
\text { Horizonte }\end{array}$ & Recife & Fortaleza & Manaus \\
\hline Energia & & 100,4 & 102,8 & 101,7 & 98,7 & 92,1 \\
\hline Proteinas & & 215,4 & 191,3 & 217,1 & 207,5 & 201.0 \\
\hline Cálcio & & 103,5 & 82,0 & 81,8 & 76,1 & 91,5 \\
\hline Ferro & & 118,0 & 91,4 & 126,8 & 113,4 & $i 54,2$ \\
\hline Vitamina-A & & 84,3 & 79,8 & 84,4 & 64,2 & 70,1 \\
\hline Tiamina & & 135,6 & 124,3 & 125 & 166,0 & 76,7 \\
\hline Riboflavina & & 107,5 & 94,6 & 102 & 91,7 & 77,5 \\
\hline Niacina & & $\rightarrow$ & - & - & - & 155,0 \\
\hline Vitamina - C & & 263,1 & 207,8 & 247,1 & 158.9 & 155.6 \\
\hline
\end{tabular}

(*) - IPOF́ - Média renda.

$(*)$ - ENDEF (Fundaçăo IBGE, 1977 a e b).

TAETIA 11 - Frincipais fontes de cnergia e proteina na dieta das familias de renda média, Mianaus, 1973-1974

\begin{tabular}{l|r|r}
\hline \multirow{2}{*}{\multicolumn{1}{c|}{ Alimentos }} & Contribuiçäo & percentua! \\
\cline { 2 - 3 } & Energia & Proteína \\
\hline Pão & 17,2 & 14,7 \\
Peixes & 8,9 & 36,7 \\
Carnes & 9,5 & 19,4 \\
Feijốes & 4,4 & 7,4 \\
Arroz & 12,4 & 6,5 \\
Leite & 3,4 & 4,3 \\
Ovos & 1,0 & 1,8 \\
Açúcar & 10,3 & 0,0 \\
Farinha & 10,7 & 1,4 \\
Óleo de algodão & 5,4 & 0,0 \\
Banana & 2,4 & 0,8 \\
Manteiga & 2,3 & 0,0 \\
\hline T O T A L & & \\
& 88,3 & 93,0 \\
\hline
\end{tabular}

suficiência de proteína chega a ser o dobro das consideradas quantidades recomendadas per capita por dia sendo este fato semelhante as outras capitais de Estados do Brasil, como está mostrado na tabela 10. É difícil imaginar deficiência simples de proteína na população de Manaus.

O consumo energético é maior que os niveis recomendados somente no grupo de alta renda, e ainda mesmo assim menor do que nos outros Estados comparados, porém devemos ressaltar de que temos dúvidas se no ENDEF foram feitos os cálculos dos níveis recomendados de energia da mesma maneira que o fizemos. A OMS (WHO, 1973) recomenda que até 13 anos a previsão seja feita para uma recuperação nutricional, "Catchup Growth", independente do tamanho da criança. Então até essa idade, calculamos as necessidades baseados no $50^{\circ}$ percentil do padrão de Harvard (Stuart \& Stevenson, 1957). Depois disso usa- 
mos o $10^{\circ}$ percentil do padrão de Harvard pois é o percentil mais próximo do único estudo transversal antropométrico brasileiro (Marcondes et al., 1971). Depois de 13 anos a previsão de energia além das necessidades não conduzirá a uma recuperação do crescimento e sim à obesidade.

No ENDEF achamos que os niveis energéticos foram calculados por quilo de peso atual e assim nas crianças de baixo peso teremos recomendação a menos, e no caso de adultos obesos uma recomendação a mais, porém não foi publicada ainda a metodologia utilizada.

$\mathrm{Na}$ verdade é com a energia que encontramos os maiores problemas na determinação de uma deficiência ou excesso. Os métodos disponiveis para medir todos os fatores no balanço energético ainda não são bem precisos para condução de experiências a longo prazo (Barnes, 1976). Existem mecanismos adaptativos a insuficiência de energia e sabemos que o excesso de energia poderia levar com o tempo a obesidade. A tolerância do organismo humano ao imbalanço energético, e até que ponto o balanço negativo prejudica a capacidade de trabalho ou resistência às infecções também não estão estabelecidas.

A suficiência de energia per capita por dia ao nivel familiai parece ser um pouco deficiente. Isto não significa que dentro da unidade familiar não exístam deficiências energéticas maiores por causa da má distribuição dentro da própria família. Há maior necessidade de energia em algumas fases da vida como nas crianças, gestantes e nutrizes porém muitas vezes o acesso maior é do pai ou dos homens da família. Não conhecemos ainda nenhum estudo de distribuição de alimentos e nutrientes dentro da unidade familiar amazonense.

Considerando a reconhecida dificuldade em avaliar o consumo e a suficiência de energia, achamos válido investigar outros parâmetros, além dos de consumo, disponíveis dentro dos resultados do IPOF. Foi decentemente demonstrado que o indice de Massa Corporal (peso dividido pela altura ao quadrado) é o que meIhor define obesidade numa população, baseado em estudos de dobra cutânea (Wormsley \& Durnin, 1977). Esse índice analisado por sexo. faixa etária e classe de renda em Manaus é mostrado na Tabela 12. Mesmo que as médias pareçam semelhantes às médias de um estudo feito numa população de Londres, considerada obesa entre $30-40 \%$ (Ashwell \& North, 1977), as diferenças ainda são significativas, usando-se o " $T$ Test" $(\mathrm{P}<0.001)$ (Armitage, 1974). Porém, os limites de normalidade do indice de Massa Corporal, ainda não estão bem estabelecidos com relação à obesidade.

Uma outra definição de obesidade, mais comumente usada, é a de um peso em excesso de $120 \%$ do peso ideal para altura. Usando o

TABEla 12 - Comparação do índice de massa corporal( $\left.{ }^{*}\right)$, por sexo, por idade e por renda em adultos d€ Vianaus e de Londres

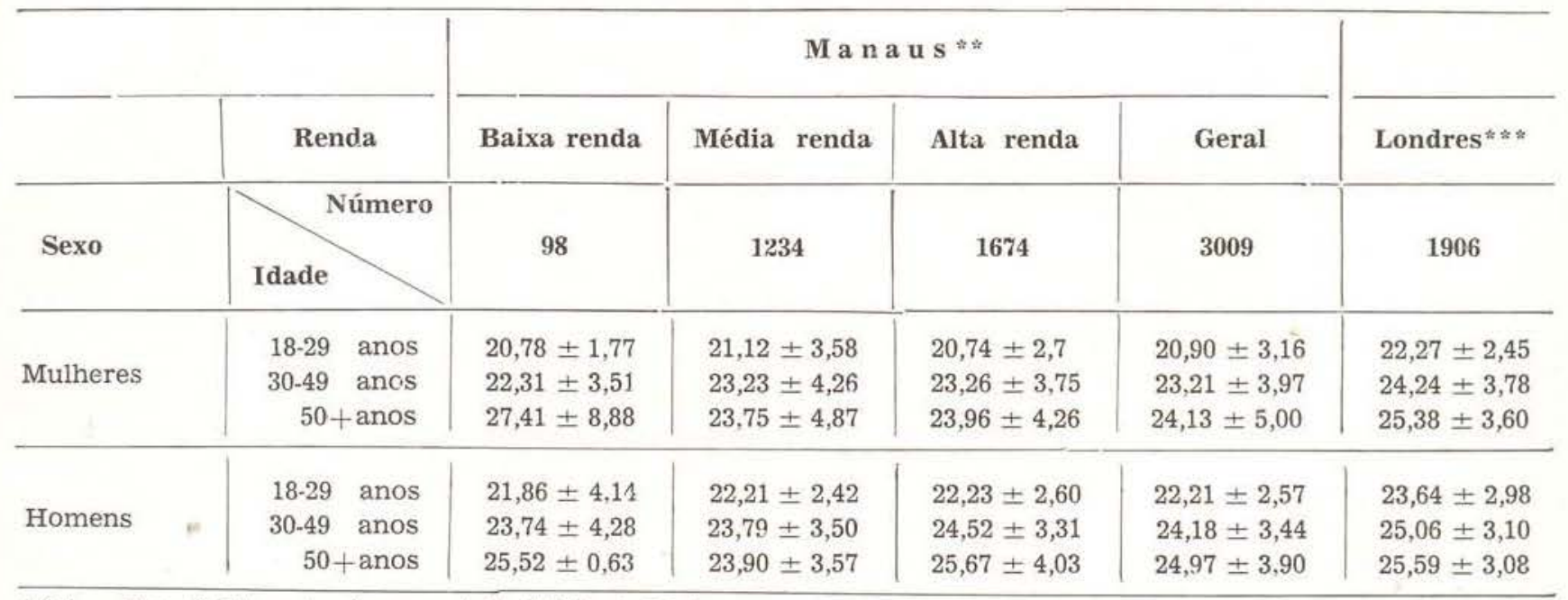

(:) - Peso dividido pela alturo quadrada (Média \pm D.P.).

$(\because)-$ IPOF.

$(* * *)$ - Ashwell \& North, 1977.

Consumo de... 
$50^{\circ}$ percentil do padrão para adultos internacionalmente reconhecido (Jelliffe, 1967), podemos observar que é o grupo de mulheres de média renda que mostra a maior freqüência de excesso de peso em Manaus (Tabela 13). Assim, podemos ainda observar que entre $10 \mathrm{e}$ $20 \%$ da população de Manaus é obesa.

Deficiência de peso por altura é freqüentemente encontrada nesta região principalmente em crianças pré-escolares e escolares (Giugliano et al., 1978b). Não analisamos os dados antropométricos das crianças porque as idades não foram bem constatadas na pesquisa. Além disso, sabemos que deficiência de peso por altura não somente reflete uma deficiência primária de energia nas crianças, mas é muito mais influenciada por infecções, especialmente diarréia, que levam a uma deficiência secundária (Whitehead et al., 1976; Waterlow \& Rutishauser, 1974.

Devemos lembrar que excesso de peso, ou obesidade, é um fator importante associado às doenças degenerativas como diabetes, arteriosclerose, e hipertensão, e que a magreza, associada a uma ingestão energética adequada ou um pouco deficiente, é a que mais promete uma vida longa e sadia para um indivíduo (Ross et al., 1976). Achamos necessários estudos mais profundos sobre os problemas de obesidade em Manaus.

\section{Cálcio}

O consumo per capita por dia de cálcio ac nivel familiar em Manaus está abaixo do recomendado, (WHO, 1961) sendo $91,5 \%$ na faixa de média renda, porém devemos lembrar que dados que permitam uma aproximação das ne-

TABELA 13 - Freqüência percentual de obesidade na população manauara acima de 22 anos de idade, por classe de renda e sexo

\begin{tabular}{l|c|c}
\hline $\begin{array}{c}\text { Grupo } \\
\text { de } \\
\text { renda }\end{array}$ & $\begin{array}{c}\text { \% das } \\
\text { mulheres } \\
\text { obesas }\end{array}$ & $\begin{array}{r}\% \text { dos } \\
\text { homens } \\
\text { obesas }\end{array}$ \\
\hline Baixa & 14.4 & 8.5 \\
Média & 21.9 & 11.4 \\
Alta & 18.2 & 14.7 \\
\hline GERAL & 19.6 & 13.1 \\
\hline
\end{tabular}

cessidades humanas ainda não são disponiveis (Linkswiler, 1976). Admitindo as necessidades, ainda imprecisas, dos níveis de cálcio para formação dos ossos, sintomas específicos deficiência de cálcio ainda não são conhecidos Depois de muitos anos de pesquisas (Irwin \& Keinholz 1973) reconhecem desconhecer uma patologia bem aefinida que possa ser atribuída a deficiência primária de cálcio em humanos (W.H.O., 1961).

A possibilidade de adaptação a uma dieta baixa em cálcio já foi mostrada (Malm, 1958) e no Perú, são conhecidos balanços de cálcio entre 300 e $400 \mathrm{mg}$ per capita por dia em populações adaptadas as baixas ingestas (Hegsted et al., 1952). Estudos recentes mostram que o nível de proteína da dieta exerce uma influência profunda sobre os níveis de cálcio urinário. Aumentando-se a ingesta protêica de 47 para $147 \mathrm{~g} /$ dia dobra os níveis de cálcio urinário (Johnson et al., 1970). Considerando-se alta ingestão protêica nas dietas manauaras e a modesta ingesta de cálcio seria de interesse estudar a freqüência de osteomalacia e/ou osteoporose no Amazonas. Sinais de raquitismo não são observados nas crianças de Manaus (Shrimpton \& Giugliano, 1977; Giugliano et al., 1978a) e nem na Amazônia (Silva, 1959).

As maiores fontes de cálcio na dieta estão na Tabela 14. Os valores de cálcio das tabelas de composição de alimentos que utilizamos

TABELA 14 - As maiores fontes de cáleio na äieta das famílias de média renda em Manaus(")

\begin{tabular}{l|c}
\hline \multicolumn{1}{c|}{ Alimentos } & Contribuição percentual \\
\hline Leite e derivacios & 13,9 \\
Farinha de mandioca & 20,4 \\
Peixes & 9,1 \\
Pão & 7,1 \\
Feijão & 4,7 \\
Sal & 4,5 \\
Arroz & 1,4 \\
Ovos & 1,4 \\
Banana & 1,0 \\
Couve & 1,0 \\
\hline \multirow{2}{*}{ TO T A L } & 88,5 \\
& \\
\hline (*) - Obesidade sendo considerada mais de $120 \%$ do peso
\end{tabular}

Shrimpton \& Giugliano 
podem ser baixos considerando por exemplo que as farinhas de mandioca locais parecem conter valores maiores que os utilizados (Lira \& Fernando, 1964). Muitos peixes são cozidos com os ossos, o que deve aumentar a quantidade de cálcio no caldo e algumas espécies também são ingeridas com os ossos pequenos inteiros como o jaraqui. Necessita-se análise dos peixes locais da maneira como são ingeridos.

\section{Ferro}

Considerando que a energia de origem animal contribui com $24 \%$ da dieta geral e $23 \%$ da dieta do grupo de médía renda, o limite superior de absorção de ferro foi considerado $15 \%$ segundo as recomendaçōes da OMS (WHO, 1970).

Mesmo assim, a dieta manauara ao nível familiar não mostrou deficiência em ferro, fornecendo $154,2 \%$ das necessidades. Por outro lado, a anemia é muito comum na Amazônia, e atinge a maioria da população devido ao alto nível de infestação por parasitas intestinais. (Giugliano et al., 1978b) .

As fontes mais importantes de ferro na dieta manauara são farinha, carne, pão, feijão e peixe (Tabela 15).

TABELA 15 - As maiores fontes de ferro na dieta das familias de média renda em Manaus, 1973-1974*

\begin{tabular}{l|c|c}
\hline \multicolumn{1}{c|}{ Alimentos } & Ferro & $\begin{array}{c}\text { Contribuição } \\
\text { percentual }\end{array}$ \\
\hline Farinha & 3,8 & 23,2 \\
Carne & 2,2 & 13,5 \\
Feijão & 2,1 & 12,8 \\
Păo & 2,0 & 12,2 \\
Peixe & 2,0 & 12,2 \\
Arroz & 0,9 & 5,5 \\
Banana & 0,3 & 1,8 \\
Ovos & 0,3 & 1,2 \\
Massa & 0,2 & 1,2 \\
Leite & 0,2 & 1,2 \\
\hline TO T A L & 14,0 & 86,0 \\
\hline
\end{tabular}

\section{Vitamina A}

Dos nutrientes considerados, a vitamina $\mathrm{A}$ parece ser a mais deficiente na dieta manauara. As familias do grupo de renda média, consum:ram somente $70 \%$ dos níveis recomendados. Não foi levado em consideração porém que as farinhas de mandioca locais são amarelas por causa do conteúdo de carotenos (Maravelhas, 1969). Se todas as farinhas consumidas tiverem igual teor das farinhas citadas por MaravaIhas o consumo per capita por dia aumentaria $40 \mathrm{mg}$ de retinol ou seja $\pm 7 \%$.

As farinhas variam muito na cor e teor de caroteno mas não sabemos ainda as freqüências de consumo das variedades amarelas na comunidade. $\mathrm{Na}$ área rural, onde o consumo de farinha é maior consideramos que ela possa ser uma fonte importante de provitamina $A$ na dieta.

Em termos nacionais a dieta manauara parece a segunda mais deficiente em vitamina $A$ vindo depois de Fortaleza e sendo pior do que em Recife. No Nordeste os erros que ocorrem pelo uso de tabelas de composição de alimentos não locais, já foi demonstrado (Coelho, 1976). É necessário confirmar os valores das tabelas de composição alimentar usadas por nós para verificar a validade de seu uso. Seria importante verificar o conteúdo da vitamina $A$ dos peixes locais como já foi demonstrado para o Nordeste (Parahym, 1952). Análise de vitamina $A$ em fígados de peixes locais já foi realizado (Albuquerque \& Mourão, 1977), porém as vísceras do peixe são pouco utilizados na dieta local.

As maiores fontes de vitamina A na dieta manauara estão na Tabela 16 . O consumo de fígado de boi é $1,5 \mathrm{~g}$ per capita por dia mas somente $33 \%$ das familias compraram-no. Talvez $60 \%$ compraram couve e $90 \%$ manteiga, mas as freqüências e quantidades cairam com a renda.

\section{Tiamina}

Na literatura antiga é muito citada a ocorrência de beribéri na Bacia Amazônica. Rodrigues (1919) refere que a mortalidade por beribéri em Manaus nos anos de 1897 a 1917 
TABELA 16 - As maiores fontes de vitamina A na dieta de familias de renda média em Manaus, 1973/74

\begin{tabular}{l|c}
\hline \multicolumn{1}{c|}{ Alimentos } & Contribuição percentual \\
\hline Figado de boi & 25,5 \\
Couve & 10,2 \\
Manteiga & 12,3 \\
Abóbora & 9,1 \\
Banana & 5,6 \\
Leite & 5,1 \\
Tomate & 2,8 \\
Pimentăo & 2,4 \\
Ovos & 3,6 \\
Cenoura & 1,6 \\
Manga & 1,7 \\
Mamão & 1,2 \\
& \\
\hline \multirow{2}{*}{ T O T A L } & 81,1 \\
\hline
\end{tabular}

variava entre 53 e 204 óbitos por ano até 1911, caindo até um por ano em 1918. Este fato está correlacionado com o declino da importação de arroz do oriente e de outros gêneros importados em péssimas condições de armazenamento durante a época áurea da borracha.

Oswaldo Cruz (1972) na região da estrada Madeira-Mamoré, quando de sua construção, salienta que o beribéri atingia, na maioria das vezes, pessoas que trabalhavam na mata, atacando desde o trabalhador até o médico. Afranio Peixoto achava que o chamado "beribéri galopante" era um verdadeiro mito (Peixoto, 1972). Djalma Batista, (1976) sugere que talvez haja outro agente, possivelmente viral, como causa do chamado "beribéri" da Amazônia, pois em 36 anos de convívio permanente com os problemas médicos da Amazônia nem ele ou médicos seus conhecidos, viram beribéri clássico no interior da Amazônia. Frente a essas informações a deficiência encontrada na dieta manauara, fornecendo somente $72 \%$ dos níveis recomendados de tiamina é interessante. Em estudos recentes no Estado do Amazonas não foram encontrados sinais clínicos de deficiência de tiamina (Giugliano et al., 1978) enquanto que no Estado do Pará parece que o beribéri ainda é encontrado (Brito et al., 1965) .
Achamos necessário um estudo mais profundo deste "Mito da Amazônia" no qual há necessidade da verificação do teor de tiamina em alimentos locais, especialmente nos peixes. e a presença ou não de tiaminases. O ácifs tânico, um componente do chá, aumenta as necessidades para tiamina. Desconhecemos se os ácidos húmicos das águas pretas da Amazônia têm a mesma influência.

\section{Riboflavina}

A Riboflavina está deficiente na dieta atingindo somente $77,5 \%$ das necessidades na população de média renda de Manaus. Este fato está apoiado pelos achados clínicos encontrados recentemente (Giugliano et al., 1978). Comparando-se com outros locais do Brasil (Fundaçăo IGBE, 1977 a e b), Manaus parece ser a mais carente em termos de riboflavina.

\section{Niacina e Ácido Ascórbico}

Para estas vitaminas a dieta parece ser suficiente e não consta na literatura achados clínicos de deficiências dessas vitaminas (Giugliano et al., 1977b) .

\section{Gorduras e Carbohidratos}

Recentemente nos Estados Unidos foram estabelecidos, por uma comissão do senado, alvos para padrões alimentares americanos a fim de diminuir os riscos das doenças degenerativas tão comuns naquele pais (U.S. Senate Select Committee, 1977). Achamos interessante, neste sentido, tentar comparar alguns aspectos do padrão alimentar manauara com os alvos dos Estados Unidos.

Com relaçắc aos carbohidratos essa comissão considerou desejável diminuir o consumo de açúcar até $15 \%$ da ingesta total de energia na dieta. $\mathrm{O}$ açúcar consumido na dieta do grupo de média renda em Manaus fornece $9,5 \%$ da energia total é o consumo de refrigerantes, sucos e doces vai contribuir com mais 1,5\% e achamos que neste sentido a dieta local se aproxima do alvo dos Estados Unidos. Ainda 


\begin{tabular}{|c|c|c|c|c|}
\hline ALIMENTOS & $\begin{array}{c}\text { Classes de ren- } \\
\text { do boixa } \\
\text { Gramas }\end{array}$ & $\begin{array}{l}\text { Classes de ren- } \\
\text { da média } \\
\text { Gramas }\end{array}$ & $\begin{array}{l}\text { Closses de ren- } \\
\text { da olto } \\
\text { Gromas }\end{array}$ & $\begin{array}{l}\text { Classes de ren- } \\
\text { do geral } \\
\text { Gromos }\end{array}$ \\
\hline Arroz amarelão & 0.91 & 2.05 & 4.52 & 3.31 \\
\hline Arroz agulha & 9.48 & 6.38 & 20.09 & 13.75 \\
\hline Arroz agulhão & 2.24 & 0.52 & 5.19 & 3.05 \\
\hline Arroz polido & 0.00 & 0.79 & 0.60 & 0.66 \\
\hline Arroz do sul & 1.37 & 1.00 & 0.62 & 0.81 \\
\hline Arroz comum & 48.02 & 44.09 & 29.03 & 36.28 \\
\hline Arroz s/especificação & 0.00 & 18.99 & 13.69 & 15.45 \\
\hline Farinha de trigo & 1.60 & 1.70 & 4.44 & 3.14 \\
\hline Maizena & 0.74 & 1.53 & 1.29 & 1.37 \\
\hline Aveia & 0.60 & 0.44 & 0.99 & 0.74 \\
\hline Pão comum & 119.44 & 112.78 & 128.67 & 121.44 \\
\hline Pẫo de forma (unidade) & 0.47 & 1.03 & 1.61 & 1.31 \\
\hline Bolacha Maria (local) & 1.39 & 1.17 & 2.05 & 1.64 \\
\hline Bolacha Maria (nacional) & 0.26 & 0.23 & 0.69 & 0.48 \\
\hline Bolacha Cream Crackrs (local) & 1.57 & 2.28 & 3.33 & 2.81 \\
\hline Bolacha Cream Crackrs (nacional) & 0.00 & 0.20 & 1.88 & 1.08 \\
\hline Bolacha Cream Crackrs (estrangeira) & 0.00 & 0.03 & 0.07 & 0.05 \\
\hline Bolacha água e sal (local) & 2.17 & 2.54 & 2.45 & 2.48 \\
\hline Bolacha água e sal (nacional) & 0.06 & 0.42 & 0.52 & 0.46 \\
\hline Bolacha água e sal (estrangeira) & 0.00 & 0.00 & 0.02 & 0.01 \\
\hline Biscoitos nacionais & 0.00 & 0.77 & 1.92 & 1.35 \\
\hline Massas (talharim, espaguete, etc.) local & 10.50 & 10.83 & 11.95 & 11.41 \\
\hline Massas (talhorim, espaguete, etc.) nac./estrag. & 1.42 & 0.71 & 1.45 & 1.13 \\
\hline Massas p/sopa & 0.43 & 0.65 & 1.46 & 1.07 \\
\hline Batata doce & 5.77 & 5.35 & 8.04 & 6.79 \\
\hline Batata inglesa & 7.23 & 6.81 & 15.11 & 11.21 \\
\hline Mandioca ou aipim & 0.00 & 0.43 & 1.49 & 098 \\
\hline Inhame & 0.00 & 0.00 & 0.14 & 0.07 \\
\hline Cara roxo & 0.86 & 0.21 & 1.26 & 0.83 \\
\hline Cara branco & 1.40 & 0.55 & 1.11 & 0.88 \\
\hline Farinha d'água do arini & 1.80 & 2.18 & 6.90 & 4.66 \\
\hline Farinha d'água comum & 30.02 & 32.74 & 25.83 & 28.98 \\
\hline Farinha seca & 38.19 & 34.95 & 29.79 & 32.35 \\
\hline Açúcar comum & 51.35 & 42.69 & 36.86 & 39.95 \\
\hline Açúcar grosso & 0.00 & 1.83 & 1.08 & 1.36 \\
\hline Açúcar refinado & 7.42 & 12.06 & 22.47 & 17.38 \\
\hline Goiabada & 1.60 & 2.14 & 5.26 & 3.77 \\
\hline Feijão branco & 1.41 & 0.03 & 0.24 & 0.20 \\
\hline Feijāo preto & 2.34 & 1.17 & 2.74 & 2.04 \\
\hline Feijão de praia & 2.09 & 1.11 & 1.38 & 1.29 \\
\hline Feijão do sul rajado & 18.68 & 20.73 & 21.23 & 20.91 \\
\hline Feijão mulato & 0.00 & 0.30 & 0.77 & 0.54 \\
\hline Feijăo manteigão & 2.47 & 2.52 & 4.88 & 3.76 \\
\hline Feijão enxofre & 2.75 & 1.91 & 1.79 & 1.88 \\
\hline Cheiro verde/cebolinha/chicória & 1.81 & 1.78 & 2.08 & 1.94 \\
\hline Couve & 2.02 & 2.29 & 3.27 & 2.79 \\
\hline Alface & 0.91 & 1.49 & 3.58 & 2.57 \\
\hline Repolho & 1.33 & 2.38 & 6.33 & 4.43 \\
\hline Alho & 0.99 & 0.82 & 1.08 & 0.97 \\
\hline Cebola & 6.70 & 7.82 & 11.03 & 9.48 \\
\hline Quiabo & 1.23 & 0.33 & 2.86 & 1.91 \\
\hline Tomate local & 7.41 & 7.00 & 8.68 & 7.90 \\
\hline
\end{tabular}


Classes de renda baixa

Gramas
Classes de renda alta Gramos
Classes de renda geral Gramas
Tomate de fora

Feijão de corda

Jerimum (abóbora) caboclo

Jerimum (abóbora) de leite

Milho verde

Cenoura

Pimentăo

Maxixe

Pepino

Pimenta murupi

Azeitona em conserv'

Ervilha em conserva

Mamão

Laranja comum

Laranja da terra

Laranja pera

Laranja da baia

Laranja lima

Laranja seleta

Limāo

Maçä

Banana maçã

Banana prata

Banana baé

Banana ouro (najá)

Banana São Tomé

Banana pacovã

Maracujá comum

Abacaxi

Abacate

Manga comum

Filé mignon

Chã de fora

Chã de dentro

Alcatra

Contra filé

Patinho

Picadinho

Outras carnes de 1."

Pá

Costela

Agulhs

Peito e pescoço

Outras carnes de 2. ${ }^{\text {a }}$

Carne de galinha/frango (vivos)

Carne de galinha/franco (abatidos)

Carne de galinha/frango ((abatidos - estrg.)

Fígado de boi

Bucho

Charque ou carne seca (jabá)

Salsicha (lata) - nacional

Salsicha (lata) - estrg.

\subsection{9}

1.00

2.54

0.07

5.33

0.00

1.74

1.63

1.06

0.51

0.37

0.36

1.92

0.90

0.00

0.00

0.10

0.00

0.00

4.32

0.00

49.36

10.36

0.00

0.00

0.00

0.48

2.12

0.93

5.33

0.00

0.21

4.94

11.92

18.58

0.00

0.00

1.47

0.00

7.07

3. 70

11.07

4.86

6.36

1.10

9.66

0.00

0.85

2.59

2. 60

0.10

0.00
2. 19

1.22

3.13

0.49

0. 46

0.21

2.36

1. 46

1.56

0.20

0.50

0.48

5,18

2. 74

0.02

0.00

0.86

0.00

0.07

4.98

0.67

39.08

12.03

0.18

0.00

0.02

1.08

2. 37

0.80

4.17

1.00

0.08

3. 23

7.61

17.11

0.70

0.29

0.9 ?

0.84

8.30

10.92

6.09

2. 96

1. 10

2.76

11.40

0.02

1.53

2.04

2.52

0.40

0.06
6.02

2.55

3.88

0.64

0.97

1.63

4. 54

3.55

3.31

0.41

1.97

1.59

9.71

8.76

0.07

0.18

0.00

0.04

0.05

7.40

2.67

48.26

16.07

0.32

0.01

0.08

1.67

6. 71

5.62

10.82

2.93

2. 28

6. 22

19.11

35.79

1. 68

0.48

0.79

6. 81

6.04

4.06

4.54

1.20

0.65

3.13

23.07

0.23

3.14

2. 03

3.76

0.85

0.06
4.18

1.91

3.50

0.55

0.92

0.95

3.49

2.57

2.46

0.32

127

?.06

7.45

5.85

0.05

0.09

0.37

0.02

0.06

6.23

1.70

44.33

14.10

0.25

0.00

0.05

1. 37

4.65

3.35

7.73

1.98

1. 25

5.18

13.85

27.04

1.19

0.38

0.87

3.96

7.05

7.01

5.47

2.11

1.07

2.89

17. 50

0.13

2. 35

2.06

3.18

0.63

0.06 


\begin{tabular}{|c|c|c|c|c|}
\hline ALIMENTOS & $\begin{array}{l}\text { Classes de ren- } \\
\text { da baixa } \\
\text { Gramas }\end{array}$ & $\begin{array}{l}\text { Closses de ren- } \\
\text { da média } \\
\text { Gramos }\end{array}$ & $\begin{array}{l}\text { Closses de ren- } \\
\text { da alta } \\
\text { Gramos }\end{array}$ & $\begin{array}{c}\text { Closses de ren- } \\
\text { da geral } \\
\text { Gramas }\end{array}$ \\
\hline Ovos de galinha - comum & 4.45 & 5.86 & 10.13 & 8.06 \\
\hline Ovos de galinha - granja & 8.05 & 7.40 & 12.44 & 10.09 \\
\hline Pescada & 0.96 & 0.92 & 3.26 & 2.16 \\
\hline Tucunaré & 1.77 & 2.70 & 4.93 & 3.84 \\
\hline Matrichão & 5.72 & 6.12 & 3.02 & 4.46 \\
\hline Tambaqui & 83.94 & 65.80 & 55.88 & 6127 \\
\hline Sardinha & 5.05 & 3.90 & 5.54 & 3.73 \\
\hline Pacu & 5.96 & 6.80 & 4.46 & 5.53 \\
\hline Pirarucu & 2.22 & 1.64 & 1.90 & 1.80 \\
\hline Curimatã & 1.60 & 3.83 & 1.95 & 2.75 \\
\hline Jaraqui & 36.34 & 29.85 & 12.33 & 20.84 \\
\hline Sardinha (em lata) - nacional & 0.21 & 0.28 & 0.65 & 0.47 \\
\hline Sardinha (em lata) - estrg. & 0.02 & 0.02 & 0.04 & 0.03 \\
\hline Pirarucu seco & 0.85 & 1.61 & 1.65 & 1.60 \\
\hline Atum (em lata) nacional & 5.97 & 16.02 & 11.57 & 13.27 \\
\hline Leite in natura & 7.69 & 0.95 & 11.48 & 6.78 \\
\hline Leite fresco (pasteurizado) - local & 11.23 & 6.13 & 7.25 & 6.92 \\
\hline Leite em pó solúvel nac. reconstituído & 55.65 & 63.53 & 82.79 & 73.44 \\
\hline Leite em pó solúvel estrg. reconstituído & 1.13 & 7.34 & 7.04 & 7.16 \\
\hline Leite em pó instantaneo nac. reconstituído & 1.67 & 1.96 & 1.95 & 1.95 \\
\hline Leite em pó instantaneo estrg. reconstituído & 0.00 & 0.59 & 0.42 & 0.48 \\
\hline Leite condensado nac. reconstituído & 14.66 & 14.00 & 17.82 & 16.04 \\
\hline Leite condensado estrg. reconstituído & 0,00 & 0.89 & 1.27 & 1.05 \\
\hline Leite infantil reconstituído & 8.82 & 11.39 & 7.45 & 9.21 \\
\hline Queijo tipo manteiga local & 0.02 & 0.07 & 0.57 & 0.33 \\
\hline Queijo tipo coalha local & 0.13 & 0.20 & 0.52 & 0.36 \\
\hline Queijo tipo coalha & 0.05 & 0.06 & 0.05 & 0.05 \\
\hline Queijo tipo prato nacional & 0.05 & 0.23 & 1.32 & 0.80 \\
\hline Queijo tipo prato estrang. & 0.00 & 0.06 & 0.31 & 0.19 \\
\hline Creme de leite, nacional & 0.12 & 0.24 & 1.03 & 065 \\
\hline Creme de leite, esirang. & 0.00 & 0.77 & 0.00 & 0.33 \\
\hline Manteiga local & 2.74 & 1.48 & 3.93 & 2.82 \\
\hline Manteiga nacional & 2.96 & 5.15 & 4.84 & 4.90 \\
\hline Manteiga estrangeira & 0.04 & 0.14 & 0.36 & 0.25 \\
\hline Óleo de algođão & 14.49 & 12.93 & 13.28 & 13.17 \\
\hline Oleo de milho & 1.22 & 0.58 & 1.72 & 1.21 \\
\hline óleo de amendoîm & 0.48 & 0.73 & 0.70 & 0.70 \\
\hline Óleo de soja & 0.28 & 0.93 & 0.91 & 0.90 \\
\hline Óleo de oliva (azeite) - nacional & 0.29 & 0.19 & 0.65 & 0.43 \\
\hline Oleo de oliva (azeite) - estrang. & 0.14 & 0.02 & 0.18 & 0.11 \\
\hline Chocolate em pó & 0.00 & 0.12 & 0.04 & 0.07 \\
\hline Chocolate/leite em pó (nescau, toddy, etc.) & 1.96 & 3.87 & 6.90 & 5,40 \\
\hline Sal - nacional & 9.77 & 8.91 & 9.26 & 9.13 \\
\hline Sal - estrg. & 0.00 & 0.04 & 0.11 & 0.08 \\
\hline Vinagre & 2.93 & 2.72 & 4.18 & 3.50 \\
\hline Pimenta-do-reino & 1.05 & 0.79 & 1.00 & 0.91 \\
\hline Massa de tomate & 0.04 & 0.29 & 0.98 & 0.65 \\
\hline Coloral & 1.20 & 1.08 & 1.19 & 0.65 \\
\hline Café em pó & 11.10 & 11.51 & 13.83 & 12.72 \\
\hline Suco de açai & 0.00 & 0.31 & 0.59 & 0.45 \\
\hline Suco de bacaba & 1.20 & 3.22 & 3.23 & 3.15 \\
\hline Guaraná (garrafa grande), local & 39.48 & 41.54 & 76.40 & 59.88 \\
\hline Guaraná (garrafa pequena), local & 0.00 & 0.74 & 1.35 & 1.03 \\
\hline
\end{tabular}




\begin{tabular}{lcccc}
\hline \multicolumn{1}{c}{ ALIMENTOS } & $\begin{array}{c}\text { Classes de ren- } \\
\text { da baixa } \\
\text { Grames }\end{array}$ & $\begin{array}{c}\text { Closses de ren- } \\
\text { da média } \\
\text { Gramas }\end{array}$ & $\begin{array}{c}\text { Closses de ren- } \\
\text { da olto } \\
\text { Gramas }\end{array}$ & $\begin{array}{c}\text { Classes de ren- } \\
\text { da geral } \\
\text { Gramas }\end{array}$ \\
\hline Guaraná, nacional (gf. comum) & 3.88 & 5.66 & 7.33 & 6.47 \\
Coca-Cola (tamanno família) & 0.64 & 2.43 & 7.62 & 5.10 \\
Coca-Cola (gf. comum) & 1.23 & 3.39 & 6.75 & 5.08 \\
Pepsi-Cola (tamanho família) & 0.00 & 0.23 & 1.42 & 0.85 \\
Pepsi-Cola (gf. comum) & 0.54 & 0.35 & 1.32 & 0.87 \\
Bare-Cola & 0.77 & 0.65 & 0.67 & 0.66 \\
Fanta Laranja ou Uva (tamanho família) & 9.29 & 11.28 & 9.99 & 10.52 \\
Fanta Laranja ou Uva (gf. comum) & 0.99 & 2.55 & 3.79 & 3.15 \\
Mirinda Laranja ou Uva (gf. comum) & 0.00 & 0.12 & 0.49 & 0.31 \\
Cerveja (gf. grande) - iocal & 0.12 & 1.24 & 4.69 & 3.02 \\
Cerveja (gf. grande) - nacional & 1.13 & 1.17 & 2.04 & 1.63 \\
\end{tabular}

ligado aos carbohidratos foi sugerido o aumento no consumo de carbohidratos complexos até $45 \%$ do total de energia cabendo portanto aos carbohidratos em geral $60 \%$ da energia global. $\mathrm{Na}$ dieta média manauara os carbohidratos contribuiram com $61,1 \%$ da energia na dieta e portanto levemente acima do nível desejado nos Estados Unidos.

$\mathrm{Na}$ Inglaterra e nos Estados Unidos são recomendados uma redução na ingestão de gorduras até $30 \%$ do consumo energético (Truswell, 1977). Na dieta média manauara as gorduras contribuem com $23 \%$ da energia total na dieta ou seja melhor do que se deseja nos países desenvolvidos. Se aumentarmos esta taxa crescerá a possibilidade de obesidade e suas implicações nas doenças degenerativas comc hipertensão, diabetes, arteriosclerose que são as maiores causas de morte nos países desenvolvidos.

\section{ComentáRtos}

O hábito de comer folhas verdes no Norte do Brasil é pouco difundido, sendo considerado comida de lagarta ou de grilo (Cascudo, 1968). A grande influência étnica do sertanejo nordestino sobre os caboclos do Norte não parece ser positiva neste sentido. Henry Koster (1811) falando sobre eles diz "de folhas verdes eles não conhecem nada e ficam rindo quando falamos em comer algum tipo de salada".
A influência indígena sobre os hábitos alimentares do nortista deve estar em decadência. O caruru é uma presença indígena e em 1820 Von Martius visitando uma aldeia de Mundurukú no Canomá, afluente do rio Madei$\mathrm{ra}$, encontrou os indígenas comendo castanhas socadas com uma erva parecida com espinafre, o caruru-açu. Ao lado estava uma cuia cheia de suco doce de favas frescas de cacau. passadas em peneira e esse era o prato nacicnal dos Mundurukú (Spix \& Von Martius, 1938). Wallace (1853) também anotou o consumo de caruru pelos indígenas do alto rio Negro. No interior ainda se encontra alguns pés de caruru, mas em Manaus o hábito sumiu.

Verduras e frutas em Manaus são ítens de luxo da dieta, sendo muito caros. Em cidades do interior o consumo de frutas era maior, ligado a presença de pomares nos quintais das casas (Lira, 1960). No desenvolvimento habitacional de Manaus o terreno que vem com a maioria das casas populares não é suficiente nem para plantar flores. Talvez neste sentido na urbanização da cidade deveriam ser plantadas, nas praças em cada conjunto residencial, fruteiras da região que são boas fontes de micronutrientes, como por exemplo manga, pupunha, buriti, tucumã, piquiá, taperebá, abricó, açaí, patoá, mari-mari, sapotilha, etc. Assim pelo menos a criançada poderia se alimentar ao mesmo tempo que estão brincando, como talvez era o caso na zona rural. 
ANEXO 2 - Tabela de composição de alimentos para uso em Manaus (por 100g de alimentos)

\begin{tabular}{|c|c|c|c|c|c|c|c|c|c|c|c|c|c|c|}
\hline & Fonte & Eng. & Prot. & Calc. & Fost. & Ferro & Vit.-A & Tiam, & Ribf. & Niac. & Vit.-C & Água & Gord & Carbh. \\
\hline irroz & A046 & 364 & 7.2 & 9 & & & 0 & & 0.03 & & & & & \\
\hline Farinha de trigo & A064 & 364 & 9.7 & 20 & 97 & $\begin{array}{l}1.3 \\
1.1\end{array}$ & 0 & 0.08 & $\begin{array}{l}0.03 \\
0.05\end{array}$ & $\begin{array}{l}1.6 \\
1.2\end{array}$ & $\begin{array}{l}0 \\
0\end{array}$ & $\begin{array}{l}12.0 \\
12.0\end{array}$ & $\begin{array}{l}0.6 \\
1.0\end{array}$ & $\begin{array}{l}73.7 \\
76.9\end{array}$ \\
\hline Maizens & A054 & 357 & 0.6 & 8 & 16 & 00 & 0 & 0.00 & 0.02 & 0.0 & 0 & 13.5 & 0.2 & $\begin{array}{l}70.9 \\
85.6\end{array}$ \\
\hline Aveia & A039 & 390 & 14.2 & 53 & 405 & 4.5 & 0 & 0.60 & 0.14 & 1.0 & 0 & 8.3 & 7.4 & 68.2 \\
\hline Pão comum & $\mathrm{A} 007$ & 317 & 10.8 & 32 & 101 & 1.8 & 0 & 0.08 & 0.06 & 1.2 & 0 & 22.9 & 1.8 & 63.1 \\
\hline Pão de forma & A006 & 307 & 9.3 & 32 & 110 & 1.7 & 0 & 0.10 & 0.06 & 1.1 & 0 & 24.1 & 0.7 & 64.4 \\
\hline Bolacha Maria & B815 & 457 & 6.1 & 126 & 94 & 0.5 & 650 & 0.03 & 0.06 & 0.4 & 0 & 4.5 & 16.9 & 10.9 \\
\hline Bolacha Cream Crackers & B918 & 439 & 9.2 & 22 & 89 & 1.5 & 0 & 0.01 & 0.05 & 1.0 & 0 & 4.0 & 13,1 & 70.6 \\
\hline Biscoitos & B411 & 369 & 7.4 & 121 & 175 & 0.5 & 0 & 0.04 & 0.10 & 0.5 & 0 & 27.4 & 17.0 & 45.8 \\
\hline Massas & A070 & 343 & 10.3 & 26 & 131 & 2.1 & 0 & 0.12 & 0.08 & 1.1 & 0 & 16.0 & 0.4 & 72.8 \\
\hline Batata doce & A258 & 116 & 1.3 & 31 & 37 & 1.0 & 30 & 0.11 & 0.04 & 0.8 & 31 & 68.9 & 0.3 & 28.6 \\
\hline Batata inglesa & A216 & 75 & 1.8 & 6 & 40 & 0.8 & 24 & 0.09 & 0.03 & 1.5 & 16 & 79.2 & 0.1 & 17.3 \\
\hline Mandioca do aipim & A112 & 148 & 0.8 & 36 & 48 & 1.1 & 5 & 0.06 & 0.04 & 0.7 & 40 & 60.6 & 0.3 & 37.4 \\
\hline Inhame - cará & A278 & 100 & 2.0 & 14 & 43 & 1.3 & 0 & 0.13 & 0.02 & 2.1 & 3 & 72.6 & 0.2 & 24.3 \\
\hline Farinha de mandioca & A114 & 320 & 1.7 & 148 & 104 & 5.4 & 0 & 0.08 & 0.07 & 1.6 & 14 & 14.2 & 0.5 & 81.0 \\
\hline Açúcar & A522 & 284 & 0.0 & 5 & 1 & 0.1 & 0 & 0.00 & 0.00 & 0.0 & 0 & 0.7 & 0.0 & 99.1 \\
\hline Goiabada & A711 & 193 & 0.5 & 13 & 13 & 0.9 & 15 & 0.01 & 0.04 & 5.0 & 54 & 50.0 & 0.1 & 49.1 \\
\hline Feijāo & A473 & 337 & 22.0 & 86 & 247 & 7.6 & 5 & 0.54 & 0.19 & 2.1 & 3 & 12.0 & 1.6 & 60.8 \\
\hline Cheiro verde/cebolinha & A188 & 31 & 1.6 & 64 & 40 & 0.7 & 210 & 0.06 & 0.09 & 0.6 & 15 & 90.3 & 0.2 & 7.1 \\
\hline Couve & A128 & 44 & 4.5 & 252 & 66 & 2.2 & 2015 & 0.16 & 0.24 & 1.2 & 125 & 85.4 & 0.7 & 7.5 \\
\hline Alface & A168 & 15 & 1.3 & 43 & 34 & 1.3 & 260 & 0.08 & 0.08 & 0.4 & 12 & 94.9 & 0.2 & 2.9 \\
\hline Repolho & A103 & 28 & 1.7 & 43 & 36 & 0.7 & 30 & 0.06 & 0.04 & 0.3 & 43 & 91.4 & 0.2 & 6.1 \\
\hline Alho & A152 & 134 & 5.3 & 38 & 134 & 1.4 & 5 & 0.21 & 0.08 & 0.6 & 9 & 63.8 & 0.2 & 29.3 \\
\hline Cebola & A186 & 45 & 1.4 & 30 & 40 & 1.0 & 4 & 0.04 & 0.03 & 0.3 & 10 & 88.1 & 0.2 & 9.7 \\
\hline Quiabo & A184 & 42 & 2.2 & 78 & 62 & 1.1 & 100 & 0.06 & 0.12 & 1.1 & 29 & 87.1 & 0.2 & 9.7 \\
\hline Tomate & A263 & 21 & 0.8 & 7 & 24 & 0.6 & 180 & 0.06 & 0.05 & 0.7 & 23 & 93.8 & 0.3 & 4.6 \\
\hline Feijão de corda & A088 & 150 & 9.8 & 59 & 213 & 3.6 & 10 & 0.38 & 0.12 & 1.5 & 7 & 60.4 & 0.3 & 27.8 \\
\hline Jarimum (abóbora) & A254 & 35 & 1.7 & 32 & 24 & 2.3 & 1145 & 0.07 & 0.05 & 0.8 & 11 & 9.1 & 0.2 & 8.1 \\
\hline Milho verde & A132 & 129 & 4.1 & 5 & 128 & 1.1 & 35 & 0.18 & 0.08 & 1.9 & 9 & 63.6 & 1.3 & 30.3 \\
\hline Cenoura & A109 & 41 & 0.8 & 34 & 26 & 0.9 & 3530 & 0.06 & 0.04 & 0.6 & 5 & 89.1 & 0.4 & 8.9 \\
\hline Pimentão & A195 & 38 & 1.9 & 20 & 28 & 1.7 & 470 & 0.09 & 0.13 & 1.5 & 91 & 88.8 & 0.6 & 8.0 \\
\hline Maxixe & A139 & 15 & 0.7 & 16 & 24 & 0.6 & 5 & 0.03 & 0.04 & 0.2 & 14 & 95.4 & 0.1 & 3.4 \\
\hline Pepino & A139 & 15 & 0.7 & 16 & 24 & 0.6 & 5 & 0.03 & 0.04 & 0.2 & 14 & 95.4 & 0.1 & 3.4 \\
\hline Pimenta murupi & A195 & 38 & 1.9 & 20 & 28 & 1.7 & 470 & 0.09 & 0.13 & 1.5 & 91 & 88.8 & 0.6 & 8.0 \\
\hline Azeitona em conserva & B1406 & 116 & 1.4 & 61 & 17 & 1.6 & 90 & 0.00 & 0.00 & 0.0 & 0 & 78.2 & 12.7 & 1.3 \\
\hline Ervilha em conserva & B1517 & 66 & 3.5 & 20 & 66 & 1.7 & 135 & 0.09 & 0.05 & 0.9 & 9 & 82.6 & 0.3 & 12.5 \\
\hline Mamão & A417 & 32 & 0.5 & 20 & 13 & 0.4 & 110 & 0.03 & 0.04 & 0.3 & 46 & 90.7 & 0.1 & 8.3 \\
\hline Laranja & A413 & 42 & 0.8 & 34 & 20 & 0.7 & 40 & 0.09 & 0.03 & 0.2 & 59 & 87.7 & 0.2 & 10.5 \\
\hline Limão & A384 & 29 & 0.6 & 41 & 15 & 0.7 & 5 & 0.06 & 0.02 & 0.1 & 51 & 90.3 & 0.6 & 8.1 \\
\hline Maçã & A286 & 58 & 0.3 & 6 & 10 & 0.4 & 10 & 0.03 & 0.05 & 0.2 & 6 & 84.0 & 0.3 & 15.2 \\
\hline Banana & A298 & 97 & 1.2 & 9 & 27 & 06 & 50 & 0.04 & 0.04 & 0.6 & 11 & 72.4 & 0.2 & 25.4 \\
\hline Maracujá & A355 & 81 & 1.9 & 9 & 39 & 2.9 & 10 & 0.00 & 0.12 & 1.9 & 15 & 78.4 & 1.3 & 17.6 \\
\hline Abacaxi & A428 & 52 & 0.4 & 18 & 8 & c. 5 & 15 & 0.08 & 0.04 & 0.2 & 61 & 85.4 & 0.2 & 13.7 \\
\hline Abacate & A291 & 92 & 1.3 & 6 & 31 & 0.8 & 15 & 0.06 & 0.10 & 1.5 & 16 & 77.0 & 15.8 & 4.4 \\
\hline
\end{tabular}


ANEXO 2 - continuação

\begin{tabular}{|c|c|c|c|c|c|c|c|c|c|c|c|c|c|c|}
\hline & Fonte & Eng. & Prot. & Calc. & Fost. & Ferro & Vit.-A & Tiam. & Ribf. & Niac. & Vit.C & Agua & Gord & Carbh. \\
\hline Mianga comum & A395 & 59 & 0.5 & 12 & 12 & 0.8 & 630 & 0.05 & 0.06 & 0.4 & 53 & 83.5 & 0.2 & 15.4 \\
\hline Carne bovina & A528 & $2+4$ & 18.7 & 4 & 207 & 3.2 & 0 & 0.06 & 0.17 & 4.3 & 0 & 62.1 & 18.2 & 0.0 \\
\hline Carne de galinha & A536 & 246 & 18.1 & 10 & 201 & 1.8 & 20 & 0.06 & 0.14 & 7.7 & 2 & 62.1 & 18.7 & 0.0 \\
\hline Figado de boi & A563 & 134 & 19.8 & 11 & 278 & 5.1 & 8660 & 0.26 & 2.37 & 8.9 & 11 & 71.2 & 3.9 & 3.6 \\
\hline Bucho & A559 & 220 & 11.0 & 12 & 110 & 1.8 & 0 & 0.04 & 0.16 & 2.0 & 0 & 69.2 & 19.1 & 0.0 \\
\hline Charque ou carne seca (jabá) & A532 & 317 & 64.8 & 93 & 161 & 9.7 & 0 & 0.02 & 0.25 & 14.8 & 0 & 16.3 & 4.5 & 0.0 \\
\hline Salsicha (lata) & B2022 & 240 & 14.0 & 8 & 153 & 2.1 & 0 & 0.08 & 0.13 & 2.6 & 0 & 63.0 & 19.8 & 0.3 \\
\hline Ovos de galinha & A599 & 148 & 11.3 & 54 & 204 & 2.5 & 125 & 0.14 & 0.37 & 0.1 & 0 & 75.3 & 9.8 & 2.7 \\
\hline Pescada & A621 & 99 & 19.6 & 27 & 197 & 0.8 & 0 & 0.04 & 0.08 & 3.0 & 0 & 75.7 & 1.7 & 0.0 \\
\hline Tucunaré & A621 & 99 & 19.6 & 27 & 197 & 0.8 & 0 & 0.04 & 0.08 & 3.0 & 0 & 75.7 & 1.7 & 0.0 \\
\hline Matrichāo & A631 & 165 & 21.3 & 30 & 252 & 2.1 & 0 & 0.24 & 0.33 & 14.4 & 0 & 69.4 & 8.2 & 0.0 \\
\hline Tambaqui & A621 & 99 & 19.6 & 27 & 197 & 0.8 & 0 & 0.04 & 0.08 & 3.0 & 0 & 75.7 & 1.7 & 0.0 \\
\hline Sardinha & A631 & 165 & 21.3 & 30 & 252 & 2.1 & 0 & 0.24 & 0.33 & 14.4 & 0 & 69.4 & 8.2 & 0.0 \\
\hline Pacu & A631 & 165 & 21.3 & 30 & 252 & 2.1 & 0 & 0.24 & 0.33 & 14.4 & 0 & 69.4 & 8.2 & 0.0 \\
\hline Pirarucu & A621 & 99 & 19.6 & 27 & 197 & 0.1 & 0 & 0.04 & 0.08 & 3.0 & 0 & 75.7 & 1.7 & 0.0 \\
\hline Curimatā & A631 & 165 & 21.3 & 30 & 252 & 2.1 & 0 & 0.24 & 0.33 & 14.4 & 0 & 69.4 & 8.2 & 0.0 \\
\hline Jaraqui & A631 & 165 & 21.3 & 30 & 252 & 2.1 & 0 & 0.24 & 0.33 & 14.4 & 0 & 69.4 & 8.2 & 0.0 \\
\hline Sardinha em lata & A641 & 311 & 20.6 & 354 & 434 & 3.5 & 55 & 0.02 & 0.17 & 4.4 & 0 & 50.6 & 24.4 & 0.6 \\
\hline Pirarucu seco & A617 & 375 & 81.8 & 50 & 891 & 3.6 & 0 & 0.08 & 0.45 & 10.9 & 0 & 12.3 & 2.8 & 0.0 \\
\hline Atum em lata & A658 & 160 & 29.0 & 60 & 230 & 2.2 & 0 & 0.13 & 0.10 & 11.3 & 0 & 62.0 & 4.0 & 0.0 \\
\hline Leite in natura & A671 & 61 & 3.5 & 160 & 91 & 0.3 & 30 & 0.04 & 0.21 & 0.1 & 1 & 87.4 & 3.0 & 5.5 \\
\hline Leite fresco (pastsurizado) & A671 & 61 & 3.5 & 160 & 91 & 0.3 & 30 & 0.04 & 0.21 & 0.1 & 1 & 87.4 & 3.0 & 5.5 \\
\hline Leite em pó reconstituido & A671 & 61 & 3.5 & 160 & 91 & 0.3 & 30 & 0.04 & 0.21 & 0.1 & 1 & 87.4 & 3.0 & 5.5 \\
\hline Leite condens, reconstituido & A680 & 99 & 2.5 & 83 & 66 & 0.0 & 31 & 0.02 & 0.12 & 0.0 & 0 & 8.2 & 2.5 & 17.1 \\
\hline Queijo tipo manteiga local & A661 & 341 & 34.0 & 950 & 0 & 1.4 & 210 & 0.02 & 0.61 & 0.2 & 0 & 36.0 & 21.0 & 3.0 \\
\hline Creme de leite & A669 & 340 & 2.3 & 77 & 66 & 01 & 365 & 0.03 & 0.11 & 0.1 & 2 & 58.5 & 36.6 & 2.1 \\
\hline Manteiga & A683 & 743 & 1.0 & 19 & 18 & 0.2 & 840 & 0.01 & 0.00 & 0.0 & 0 & 14.9 & 84.0 & 0.0 \\
\hline Oleo vegetal & A687 & 884 & 0.0 & 0 & 0 & 0.0 & 0 & 0.00 & 0.00 & 0.0 & 0 & 0.0 & 100.0 & 0.0 \\
\hline Massa de tomate & B2295 & 82 & 3.4 & 27 & 70 & 3.5 & 3300 & 0.20 & 0.12 & 3.1 & 49 & 75.0 & 0.4 & 13.6 \\
\hline Coloral & A706 & 334 & 6.6 & 120 & 116 & 56 & 185 & 0.09 & 0.19 & 1.7 & 7 & 5.6 & 4.6 & 78.2 \\
\hline Café em pó & A710 & 226 & 12.6 & 148 & 198 & 2.9 & 0 & 0.07 & 0.05 & 17.0 & 0 & 5.0 & 14.8 & 63.4 \\
\hline Suco de açaí & $\mathrm{C}-$ & 77 & 2.4 & 50 & 28 & 0.9 & 0 & 0.00 & 0.00 & 0.0 & 0 & 0.0 & 6.0 & 3.4 \\
\hline Suco de bacaba & C - & 334 & 3.9 & 30 & 40 & 1.0 & 0 & 0.00 & 0.00 & 0.0 & 0 & 0.0 & 29.5 & 13.3 \\
\hline Vinagre & A717 & 12 & 0.0 & 7 & 10 & 0.5 & 0 & 0.00 & 0.00 & 0.0 & 0 & 0.0 & 0.0 & 3.0 \\
\hline Pimenta-do-reino & B551 & 309 & 8.8 & 127 & 130 & 10.2 & 0 & 0.06 & 0.12 & 0.6 & 69 & 0.0 & 6.5 & 68.0 \\
\hline Chocolate/leite em pó & B778 & 359 & 18.6 & 589 & 545 & 1.8 & 20 & 0.13 & 0.73 & 0.7 & 3 & 1.9 & 2.9 & 70.8 \\
\hline Sal & B1963 & 0 & 0.0 & 253 & 1 & 0.1 & 0 & 0.00 & 0.00 & 0.0 & 0 & 0.9 & 0.0 & 0.0 \\
\hline Refrigerante tipo cola & B406 & 46 & 0.0 & 0 & 0 & 0.0 & 0 & 0.00 & 0.00 & 0.0 & 0 & 88.0 & 0.0 & 12.0 \\
\hline Refrigerante tipo fruta & B404 & 39 & 0.0 & 0 & 0 & 0.0 & 0 & 0.00 & 0.00 & 0.0 & 0 & 90.0 & 0.0 & 10.0 \\
\hline Cerveja & B394 & 42 & 0.0 & 5 & 30 & 0.0 & 0 & 0.00 & 0.03 & 0.6 & 0 & 92.1 & 0.0 & 3.8 \\
\hline
\end{tabular}

FONTES: A - Leung \& Flores, 1961.

B - Wott \& Merril, 1963.

C - Franco, 1974. 
ANEXO 3 - Ingestas diárias para aỉguns nutrientes segundo recomendaçōes da ONiS

\begin{tabular}{|c|c|c|c|c|c|c|c|c|c|c|c|}
\hline & $\begin{array}{l}\text { Idade } \\
\text { anos }\end{array}$ & $\begin{array}{c}\text { Peso(1) } \\
\text { Kg }\end{array}$ & $\begin{array}{c}\text { Energia }(2) \\
\text { Calo- } \\
\text { rios(10) }\end{array}$ & $\begin{array}{c}\text { Proteí- } \\
\text { na(3) } \\
g\end{array}$ & $\begin{array}{l}\text { Vitami- } \\
\text { na A(4) } \\
\text { meg(11) }\end{array}$ & $\begin{array}{l}\text { Vitomi- } \\
\text { na C(s) } \\
\text { mg }\end{array}$ & $\begin{array}{c}\text { Nioci- } \\
\text { na(4) } \\
\text { mg }\end{array}$ & $\begin{array}{c}\text { Ribofla_- } \\
\text { vino(4) } \\
\text { mg }\end{array}$ & $\begin{array}{c}\text { Tiomi- } \\
\text { no(4) } \\
\text { mg }\end{array}$ & $\begin{array}{c}\text { Cálcio(6) } \\
\text { mg }\end{array}$ & $\begin{array}{l}\text { Ferro } \\
\text { (5.8) } \\
\text { mg }\end{array}$ \\
\hline \multirow{5}{*}{ Crianças (7) } & $0-0.5$ & 6.0 & 702 & 13.2 & 450 & 20 & 4.6 & 0.4 & 0.3 & 360 & 7.0 \\
\hline & $0.5-1.0$ & 9.0 & 972 & 19.8 & 300 & 20 & 6.0 & 0.6 & 0.5 & 500 & 7.0 \\
\hline & $1-3$ & 13.4 & 1360 & 22.8 & 250 & 20 & 9.0 & 0.8 & 0.6 & 500 & 7.0 \\
\hline & $4-6$ & 20.2 & 1830 & 29.1 & 300 & 20 & 12.0 & 1.0 & 0.8 & 500 & 7.0 \\
\hline & $7-9$ & 28.1 & 2190 & 35.3 & 400 & 20 & 14.5 & 1.2 & 0.9 & 500 & 7.0 \\
\hline \multirow[t]{6}{*}{ Masculinos } & $10-12$ & 36.7 & 2600 & 42.7 & 575 & 20 & 17.0 & 1.5 & 1.1 & 700 & 7.0 \\
\hline & $13-15$ & 46.2 & 2633 & 47.6 & 725 & 30 & 17.0 & 1.4 & 1.1 & 700 & 12.0 \\
\hline & $16-19$ & 57.0 & 27.93 & 48.8 & 750 & 30 & 18.5 & i. 4 & 1.2 & 600 & 7.0 \\
\hline & $20-39$ & 65 & 3000 & 53.0 & 750 & 30 & 20.0 & 1.7 & 1.2 & 500 & 7.0 \\
\hline & $45-49$ & 65 & 2850 & 53.0 & 750 & 50 & 19.0 & 1.6 & 1.2 & 500 & 7.0 \\
\hline & $50+$ & 65 & 2400 & 53.0 & 750 & 30 & 15.8 & 1.3 & 1.0 & 500 & 7.0 \\
\hline \multirow[t]{6}{*}{ Femininas } & $10-12$ & 37.7 & 2337 & 41.0 & 575 & 20 & 15.4 & 1.3 & 1.0 & 700 & 7.0 \\
\hline & $13-15$ & 46.5 & 2325 & 42.0 & 725 & 30 & 15.3 & 1.2 & 0.9 & 700 & 18,0 \\
\hline & $16-19$ & 50.3 & 2163 & 39.5 & 750 & 30 & 14.3 & 1.2 & 0 is & 600 & 19.0 \\
\hline & $20-39$ & 55.0 & 2200 & 41.0 & 750 & 30 & 14.5 & 1.2 & 0.9 & 500 & 19.6 \\
\hline & $40-49$ & 55.0 & 2090 & 41.0 & 750 & 30 & 13.8 & 1.2 & 0.0 & 500 & 19.0 \\
\hline & $50+$ & 55.0 & 1760 & 41,0 & 750 & 30 & 10.6 & 1.0 & 0.7 & 500 & 6.0 \\
\hline Gestantes & & & +235 & +13.0 & +0 & +50 & +2.0 & +0.2 & +0.2 & +700 & $0(8)$ \\
\hline Lactentes & & & +500 & +24.0 & +450 & +50 & +2.0 & +0.0 & +0.2 & +700 & 0 \\
\hline
\end{tabular}

\section{OBSERVAC̄ōES :}

1. Peso médio de cada faixa etária baseado no 500 percentile até 12 anos e depois no 100 percentile do Padrăo de Crescimento de Harvard-lowa (Stuart and Stevenson, 1966).

2. Who tech rept series n.o 522 (1973).

3. Proteina-odmitindo a qualidade como equivalente a $70 \%$ da proteina do ovo ou leite.

4. Who tech. Rpt. Series n.0 362 (1965).

5. Who tech. Rpt Series n.o 452 (1970).

6. Who tech Rpt Series n.0 230 (1961).

7 . Nos primieors seis meses a amamentaçäo e consideroda satisfatória para o fornecimento de todios os nutrientes necessárís.

8. Anemia na gravidez requer ferro terapêutico.

9. Admitindo alimentos animais fornece mais de $15 \%$ da energia na dieta e menos de $25 \%$.

10. Caloria $=4,186$ kilojoules.

11. Micro grama de B caroteno equivalente 0.167 microgramas de retinol.

RS-DAN-INPA, 78.

O consumo de verduras, porém, precisa de medidas educacionais, começando nas escolas como, por exemplo, a implantação de canteiros escolares estimulando o plantio de verduras e hortaliças. Mudas e sementes de variedades de legumes resistentes às pragas locais devem ser disponiveis. A divisão de Agronomia deste instituto vem se preocupando muito em desenvolver estas variedades.

A Campanha Nacional da Alimentação Escolar (CNAE) tem até influência negativa neste sentido estimulando o hábito de consumir pozinhos pré-preparados e "milkshakes" de fórmulas industriais. Brevemente vai iniciar-se em Manaus um projeto do Programa Mundial de Alimentos (PMA) que junto com o CNAE irão destribuir nas escolas de Manaus bacalhau seco, leite em pó, frutas cristalizadas e aveia. Mandar peixe seco para Manaus é um absurdo igual a mandar soja para o Rio Grande do Sul. Estimular $a$ consumo de aveia na região é outro absurdo indesejável.

Manaus está em fase de sair do subdesenvolvimento e está crescendo muito rápido. Neste processo é essencial que seja apreendido o que foi feito errado no desenvolvimento dos países já desenvolvidos, para não cometer os mesmos erros. Com relação a alimentação, os países desenvolvidos estão querendo: 19) Aumentar o consumo de frutas, legumes. verduras e grãos; $2^{\circ}$ ) Diminuir $\alpha$ consumo de carne e aumentar o consumo de peixe; $3^{\circ}$ ) $\mathrm{Di}$ - 
nuir o consumo de manteiga e ovos; $5 .^{\circ}$ ) Diminuir o consumo de açúcares e doces. Em Manaus a maior preocupação das autoridades parece estar ligada com abastecimento de carne e de leite muito mais que o fornecimento de frutas e verduras a população geral com preços acessiveis.

$\mathrm{Em}$ face as deficiências nutricionais constatadias atualmente, e os problemas que se prevê para o futuro deve-se concentrar esforços na produção e consumo de frutas, verduras e legumes e a manutenção do peixe a custo acessivel.

Com relação aos grãos, o estímulo ao consumo de trigo na Amazônia através de subsídios é condenável, devendo voltar-se o mesmo para o arroz, cuja plantação tem amplas perspetivas nesta área enquanto o trigo sempre dependera de importação.

\section{CONCLusões}

A dieta de Manaus parece satisfatória do ponto de vista quantitativo, e a obesidade já está chegando a ser um motivo de preocupação. Os nutrientes que fornecem energia estão em proporções desejáveis em relação às suas possíveis implicações no desenvolvimento de doenças degenerativas, como arteroscleroses, diabetes, hipertensão, as quais estão associadas com a obesidade.

Em termos qualitativos, a dieta de Manaus é bastante carente, sendo possivelmente uma das piores, comparadas com outras capitais do Brasil. Dos nutrientes considerados, são deficientes a Vitamina $A$, riboflavina e tiamina. A deficiência desses nutrientes diminui a resistências às infestações e infecções tão comuns no meio ambiente pouco saneado de Manaus.

Para melhorar a qualidade da dieta em Manaus e corrigir as deficiências observadas, é essencial estimular a produção e consumo de legumes, verduras e frutas, que são pouco consumidos em comparaçōes nacionais e internacionais.

Para atingir esses objetivos, é necessário salientar que projetos de distribuição de alimentos podem até ter influências negativas a longo prazo, se os alimentos distribuídos não são locais. Devem ser dirigidos para melhorar a qualidade da dieta e acompanhados de programas de educação nutricional .

\section{AGRAdecIMENTOS}

Agradecemos ao Dr. José Fernando Pereira da Silva, Secretário Executivo da CODEAMA, por permitir a análise dos dados do IPOF; Dr. Nelson Rodrigues do CPD do INPA, por seus esforços em desenvolver os programas; $\mathrm{Dr}$. Francisco Raimundo da Silva, do Núcleo de Pesquisas da CODEAMA, por sua colaboração e ajuda em interpretar as informações do IPOF, e a Regina Shrimpton pela sua ajuda na tradução e preparação do manuscrito.

\section{SUMMARY}

In view of the scarcity of literature on food consumption and nutrient intakes in the Amazon Basin, the results of a household expenditure survey conducted in 1,200 families of Manaus in 1973-74 were analyzed. The frequency of families buying different foods and the daily per caput intake of these foods, were calculated. The diet was characterized by low vegetable, low legume, low fruit, high bread, high cassava flour and high fish consumption. Using food composition tables, daily per capita intakes of energy, protein, fat, carbohydrate, calcium, iron, vitamina A, riboflavin, thiamin, niacin and ascorbic, acid were estimated and compared with calculated recommendei intakes per capita. Sufficiences of Vitamin and mineral intake in the medium wage group, considered the sample most representative of the city as a whole, were vitamin A $70,1 \%$, thiamin $76,7 \%$, riboflavine $77,5 \%$, calcium $91,5 \%$ iron $154,2 \%$, niacin $155,0 \%$ and ascorbic acid $155,6 \%$. These results are worse than those reported for some state capitals of the north-east of Brazil, where malnutrition is considered to be endemic. These deficiencies need corroboration by analasis of local foods and clinical biochemical studies of the local population. The intake of protein and energy seems sufficient since $201 \%$ of protein requirements and $92,1 \%$ of energy requirements are met. Using the body mass index in the adult population group, obesity is indicated as not being uncommon, especially in middle aged women. The distribution of energy sources as $61,5 \%$ fron carbohydrates, $21,3 \%$ from fats and $17,2 \%$ fron protein would seem satisfactory in relation to recent recommendations of governments of developed countries, where obesity and atherosclerosis are the major public health problems. Based on the food 
consumption pattern a programme to stimulate production and consumption of vegetables should probably be the main government priority to improve the local food and nutrition situation.

\section{BIBLIOGRAFIA}

albuquerque, H.C.R. \& mourño, A.P.

1977 - Ocorrência de Vitamina $\Lambda$ em óleos de fígado de peixes no Estado do Amazonas, Resumo da 29." Reuntão Anual do SPBC. São Paulo.

ARMITAGE, $P$.

1974 - Statistical Methods in Medica! Research. London, Blackwell $504 \mathrm{p}$

ASHWELL, MI. \& NORTH, W.R.S,

1977 - The prevalence of obesity in working populations of London. Proc. Sut. Soc., $36: 109$ A.

BARNES, R.H.

1976 - Energy. In: Preseni Knowiedge in Nutrition, Washington, the Nutrition INC p. 10-16.

BАтISTA, D.J.

1976 - O Complexo da Amazônia, Rio de Janeiro, Conquista. 292 p.

BERG, A.

1973 - The nutrition factor. Washington DC., The Brookings Institution. $290 \mathrm{p}$.

Ermto, R.S.; Camillo, M.V. \& Salles, J.M.C.

1965 - Aspectos da Nutriçẵo Humana no Es tado do Pará. In: Anais do 1.० Simpósio Brasileiro de Alimentação e Nutrição, Campinas S.P. p. 31-33.

CASCudo, L.C.

1968 - História da Alimentação no Brasil. São Paulo, p. $145-161$

CASTRO, J.

1965 - Geografia da Fome. Rio de Jnneiro, Editora Erasiliense, $332 \mathrm{p}$.

Chaves, $\mathrm{N}$.

1972 - Panorama Nutricional do Brasil. In: Introdução a Geografia médica do Brasil. São Paulo, Lacaz, C.S. p. 519-524.

CODEAMA

1976a - Anuário Estatística 1975. Mannus, Governo do Estado do Amazonas. 298 p.

$1976 \mathrm{~b}-\mathrm{A}$ primeira pesquisa sobre Orçamentos Familiares. Pesquisa Cadastral. Menaus, Governo do Estado do Amazonas $42 \mathrm{p}$.

1977 - Primeira pesquisa sobre Orçamentos Familiares. Dispendios e Hábitos dic Consumo. Manaus, Governo do Estedo do Amazonas. $4 \mathrm{v}$.
COELho, M.A.S.C.

1976 - Composição de Alimentos: Avaliação de Métodos em uso (Tese) Recife, Institu. to de Nutrição, $40 \mathrm{p}$.

Costa, D

1948 - Pesquisas de Nutrição na Amazônia con siclerada como "Zona Alimentar excep. cionalmente grave". Imprensa "Viédica, 24(420) : 64-66.

Costa, O. \& Silva, W.

1949 - Quatro inquéritos sobre hábitos alimen. tares. Arq. Bras. Nut., 2(2) : 6-55.

Crim, M.C. \& MUNRo, H.N.

1976 - Protein, In: Present Knowledge in Nutrition, Washington D.C. The Nutrition Foundation Inc p. 43-54.

Cruz, O.

1972 - Consideraçöes Gerais sobre as condiçôes Sanitárias do rio Madeira. In: So. bre o Saneamento da Amazônia. Manaus. Philippe Daou S.A. p. 5-44.

DA rosa E silva, G.J.

1964 - "Alimentação e subdesenvolvimento no Brasil". Revista Brasileira de Geografia, $26(3): 291-457$.

DEPARTMENT OF HEALTH AND SOCLAL SECURITY

1974 - Report on Health and Social subjjects (7) : 1-45, London, H.M. Stationery Office.

Franco, G.

1974 - Tabeia de Composição Química des Alimentos, Biblioteca Planutre, $83 p$

Fundação GETUlo VARGas

1970 - Food Consumption in Brasil. Family Budget Surveys in The eariy 1960's. Jerusalem, Kettcr Press. $271 \mathrm{p}$.

FUNDAÇÃo IBGE

1971 - Sinopse Treliminario do Censo Demegráfico - VII. Recenseamento Ceral 1970. Amazonas. Rio de Janeiro, Fundação Instituto de Geografia e Estatística, $47 \mathrm{p}$.

1977a - Estudo Nacional de Despesa Familiar. Consumo Alimentar Antropométria, dàdos Preliminares da Rcgião $\nabla$. Filo de Janeiro, Fundação Instituto Brasileiro de Geografia e Estatística. 72 p

1977b - Estudo Nacional de Despesa Familiar Consumo Alimentar Antropométria Dodos Preliminares das Regiōes पI e IV. Fio de Janeiro, Fundação Instituto Brasilciro de Geografia e Estatística 110 p.

Garzi, C, \& SCrimshaw, N.S.

1976 - Relationship of lactose intoierance to milk intolerance in young childron. $A m$. J. Clin. Nutr., 29 : 192-196. 
Giugliano, R. \& Shrimpton, R.

1977 - Estudo anthropométrico e clínico do estado nutricional em um grupo de crianças pré-escolares de Manaus. Acta Ama. zonica, $7(3): 389-394$.

Grugliano, R.; Albuquerque, H.C.R \& Shrimpton, R. 1978a - Estudo anthropométrico, clínico, e de padrōes alimentares em um grupo de escolares de Manaus. Acta Amazonica, $8(1)$.

Giugliano, R.; SHrImpton, R.; Arckell, D.B.; Giugliano, L.G. \& Petrerre, M. 1978b - Acta Amazonica, 8(2) Supl. 174 p.

GURR, M.I. \& KIRTLAND, J.

1976 - Obesity. Chemistry and Industry, 18: 766-771.

Hanson, E.

1933 - Malnutrition in the Amazon Basin. Science, $78: 36-38$.

Hegsted, D.M.; Moscoso, I. \& Collazoe, CH. C. 1952 - A study of the minimum calcium requirements of adult men. J. Nutr., 46 : 181-201.

ICNND

1965 - Northeast Brasil Nutrition Survey. Washington D.C., Interdepartmental Committee on Nutrition for national development. $294 \mathrm{p}$.

IRWIN, M.I. \& KIENHOLZ, E.W.

1973 - A conspectus of Research on calcium requirements of man. J. Nutr., 103 ; 1019-1095.

JANSEN, G.R.; JANSEN, N.B.; SHIGetomi, C.T.; \& HARPER, J.M.

1977 - Effect of income and Geographic region on the nutritional value of diets in Brazil. Am. J. Clin. Nutr., 30 : 955-964.

JELLIFFE, D.B.

1966 - The assessment of the nutritional stutus of the communty World Health Organization Monograph series $53: 0-272$

1968 - Infant nutrition in the subtropics and tropics. World Health Organization Monograph series $29: 0-334$.

Johnson, N.F.; Alcantara, E.N. \& Linkswiler, H.M.

1970 - Effect of level of protein intake on urinary and fecal calcium and calcium retention of young adult males. J. Nutr., $100: 1425-1430$.

KOSTER, H.

1811 - Viagens ao Nordeste do Brasil, Apud Cascudo, C.C. História da Alimentação no Brasil, São Paulo. V. 2, $151 \mathrm{p}$.
Leung, W.W. \& Flores, M.

1961 - Food composition tables for use in Latin America, Maryland, U.S.A. INCAP. ICNND, $145 \mathrm{p}$.

LINKSWILER, H.M.

1976 - Calcium. In: Present Knowledge in Nutrition. Washington, The Nutrition Froundation Inc. p. 232-240.

LIRA, M.B.

1960 - Levantamento de dados alimentares em cidades do interior Amazônico. Revista Brasileira de Medicina, 17(7): 636 .

LIRA, M.B. \& FERNANDES, E.

1964 - Bromatologia das farinhas de mandioca produzidas no Amazonas, Manaus. Publicação do INPA ser, Química, $7: 1-8$.

MALM, O.J.

1958 - Calcium requirement and adaption in adult men. Scand J. Clin Lab. Invest, 10 (Suppl) : 1.289.

Maravalhas, N.

1964 - Cinco estudos sobre a farinha de man. dioca. Manaus. Publicaçāo do INPA ser. Química, $4: 1-41$.

Marcondes, E.; Berquó, E.S.; Yunes, J.; Martins, J.S.; ZACCHI, M.A.S.; LeVY, M.S F. \& HEGG, R.

1971 - Estudo antropométrico de crianças brasileiras de zero a doze anos de idade. Anais Nestlé (84) : 200 .

Mata, L.T.; Kromal, R.A.; Urruti, J.J. \& Garcis, B. 1977 - Effect of infection on food intake and the nutrition state: Perspectives as viewed from the village. Am J. Clin. Nutr. $30: 1215-1227$.

MCLAREN, D.S.

1975 - The Great protein fiasco. Lancet, 11 : 93-96.

MULler, M.

1974 - The Baby Killer. London, War on Wart. $19 \mathrm{p}$.

PARAHYM, O.

1952 - Peixes do Nordeste como fonte de vitamina A. Apud: Da Rosa e Silva, G.J. 1964. Revista Brasileira de Geografia, $26(3): 29-457$.

PEIXoto, A.

1972 - O problema sanitário na Amazônia, In: "Sobre o saneamento da Amazônia". Manaus, Philippe Daou S/A p. 177-205.

REH, E.

1962 - Manual on household food consumption surveys. Rome, FAO Nutritional Studies (18) $1-96$. 
RODRIGUES, $\mathrm{F}$.

1919 - Beri Beri experimental e Beri Beri humano com especial referência as formas observada no Amazonas. Memórias do Instituto Oswaldo Cruz (1) : 90-120.

Ross, M.H.; Lustbader, E. \& Bras, G.

1976 - Dietary practices and growth responses as predictors of Longevity. Nature, $262: 548-553$.

ROSENSWEIG, N.S.

1973 - Lactose feeding and lactase dicficiency. Am. J. Clin. Nutr. $26: 1166-1167$.

SALOMON, J.B. \& DÓREA, J.G.

1977 - Perfil da Alimentação Brasileira. Relação entre calorias e proteínas. Revista Abia/Sapro, $33:$ 14-29,

SHRIMPTON, R.

1976 - Nutrition and development in Brazil. (Masters disertation), Londres. University of London, $126 \mathrm{p}$.

Shrimpton, R. \& Giugliano, R.

1977 - Nutrição em lactentes de um bairro de Manaus-Amazonas. Acta Amazonica, $7(2): 247-253$.

SILva, W.

1959 - Inquérito sobre consumo de Alimentos e Nutrimentos. Avaliação do estado nutritivo e situação econômica da população da Amazônia. Boletim da Comissão Nacional de Alimentação, (2) : 1-60.

Simoons, F.J.

1978 - Traditional use and Avoidance of foods of animal origin. A culture historical view. Bioscience, $28(3)::$ 178-184.

SNYDER, W.S.; COOK, M.J.; NASSET, E.S.; KARHAUSEN, L.R.; Howel.LS, G.P. \& TiPTON, I.H.

1975 - Report of the task group on reference man. International Comission on Ra. diological Protection Publication (23): 480 .

SPIX, J.B. \& VON MArtius, C.F.P.

1938 - Viagem pelo Brasil. Tradução de D. Lucia Furquim Lahmeyer, Rio de Janeiro.

StuArT, H.C. \& Stevenson, S.S.

1957 - Physical growth and development. In: Textbook of Pediatrics. Philadelphia, W.E. Nelson, p. 10-66.

SUKАTME, P.V.

1977 - "Nitrogen in Malnutrition", paper presented at nobel symposium "Nitrogen-an essentia! life factor and Growing environmental razard". Stockholm, Royal Swedish Academy of sciences, (inédito).
Truswell, A.S.

1977 - The need for change in food habits fron a medical viewpoint, Proc. Nut. Soc., $36: 307-316$.

U.S. SENATE SELECT COMMITTEE ON NUTRITION AND HUMAN NEEDS

1977 - Dietary goals for the United States. Washington D.C., U.S. $95^{\text {th. }}$ Congress.

Wallace, A.R.

1853 - A narrative of travels on the Amazon and rio Negro. London, $541 \mathrm{p}$.

WATERLOW, J.C. \& RUtishauser, I.H.E.

1974 - Malnutrition in man. In: Early Malnutrition and Mental Development. Stockholm, Almquist and Wiksell p. 13-26.

WATERlow, J.C. \& PAyne, P.R.

1975 - The protein gap. Nature, 258: 113-117

WATt, B.K. \& MERRIL, A.L.

1963 - Composition of foods. Washington D.C. (Agricultural Hand Book, 8) U.S.D.A. $190 \mathrm{p}$.

Whitemead, R.G.; Rowland, M.G.M. \& Cole, T.G.

1976 - Infection, nutrition and growth in a rural african environment. Proc. Nutr. Soc., $35: 369-375$.

W.H.O.

1961 - Calcium Requirements. Tech Rpt. Series (230) : 1-54.

1965 - Requirements of vitamin A, Thiamine, Riboflavina and Niacin. Tech Rpt. Series (362) : 1-86.

1970 - Requirements of Ascorbic Acid, Vitamin $\mathrm{D}$, Vitamin $\mathrm{B}_{12}$, Folate and Iron. Tech Rpt. Series (452) : $1-75$.

1973 - Energy and protein requirements. Tech Rept. Series (522) : 1-118.

WISNIEWSKY, A. \& LISBONATI, V.F.

1967 - Alguns aspectos da Alimentação na Amazônia. Belém, IPEAN (mimeografado).

WORMSLEy, J. \& DURnin, J.V.G.A.

1977 - A comparison of the skinfold method with extent of overweight and various weight-height relationships in the assessment of obesity. Br. J. Nutr., 38 : 271-284.

(Aceito para publicação em 14/12/78) 